Gelbrich, Katja; Roschk, Holger:

\title{
A meta-analysis of organizational complaint handling and customer responses
}

URN: $\quad$ urn:nbn:de:gbv:ilm1-2014210204

Published OpenAccess: October 2014

Original published in:

Journal of service research. - London : Sage Periodicals Press (ISSN 1552-7379).

- 14 (2011) 1, S. 24-43.

DOI: $\quad 10.1177 / 1094670510387914$

URL: $\quad$ http://dx.doi.org/10.1177/1094670510387914

[Visited: 2014-10-14]

„Im Rahmen der hochschulweiten Open-Access-Strategie für die Zweitveröffentlichung identifiziert durch die Universitätsbibliothek IImenau."

"Within the academic Open Access Strategy identified for deposition by Ilmenau University Library."

„Dieser Beitrag ist mit Zustimmung des Rechteinhabers aufgrund einer (DFG-geförderten) Allianz- bzw. Nationallizenz frei zugänglich."

"This publication is with permission of the rights owner freely accessible due to an Alliance licence and a national licence (funded by the DFG, German Research Foundation) respectively."

\section{DFG}

Nationallizenzen 


\section{Journal of Service Research \\ http://jsr.sagepub.com/}

\section{A Meta-Analysis of Organizational Complaint Handling and Customer Responses \\ Katja Gelbrich and Holger Roschk}

Journal of Service Research 2011 14: 24 originally published online 3 December 2010

DOI: $10.1177 / 1094670510387914$

The online version of this article can be found at:

http://jsr.sagepub.com/content/14/1/24

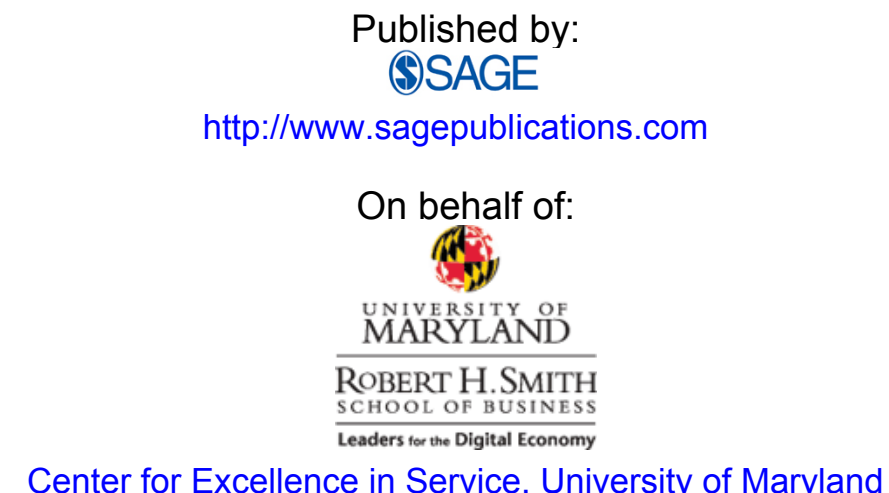

Additional services and information for Journal of Service Research can be found at:

Email Alerts: http://jsr.sagepub.com/cgi/alerts

Subscriptions: http://jsr.sagepub.com/subscriptions

Reprints: http://www.sagepub.com/journalsReprints.nav

Permissions: http://www.sagepub.com/journalsPermissions.nav

Citations: http://jsr.sagepub.com/content/14/1/24.refs.html

>> Version of Record - Dec 29, 2010

OnlineFirst Version of Record - Dec 3, 2010

What is This? 


\title{
A Meta-Analysis of Organizational Complaint Handling and Customer Responses
}

Journal of Service Research 14(I) 24-43

(C) The Author(s) 2011

Reprints and permission:

sagepub.com/journalsPermissions.nav DOI: $10.1177 / 1094670510387914$

http://jsr.sagepub.com

(SAGE

\author{
Katja Gelbrich' and Holger Roschk'
}

\begin{abstract}
Service recovery is a crucial success factor for organizations. Thus, many studies have addressed the issue of post-complaint behavior. Conducting a meta-analysis, the authors test the following path model: "organizational responses (compensation, favorable employee behavior, and organizational procedures) $\rightarrow$ justice perceptions (distributive, interactional, and procedural justice) $\rightarrow$ post-complaint satisfaction (transaction-specific and cumulative satisfaction) $\rightarrow$ customer behavioral intentions (loyalty and positive word of mouth [WOM])." The results confirm this model as well as the mediating role of justice perceptions and post-complaint satisfaction. Surprisingly, the results also show that the common contention of distributive justice as the salient driver of service recovery is only true for transaction-specific satisfaction, which in turn reinforces positive WOM. Cumulative satisfaction, however, which is the primary antecedent of customer loyalty, even slightly more depends on interactional justice than on distributive justice. Further, the results show that the relationships between justice perceptions and satisfaction constructs depend on several moderators such as target group, industry, and complaint type. A major managerial implication is the fact that organizations should pay particular attention to distributive justice when complainants are students and to interactional justice when failure is nonmonetary or occurs in service industries. The authors discuss theoretical implications and provide suggestions for future research.
\end{abstract}

\section{Keywords}

service recovery, meta-analysis, consumer complaints, customer satisfaction, complaint management

\section{Introduction}

The topic of post-complaint behavior has received considerable attention in the marketing literature. Pioneering studies examine the effect of different organizational responses to a complaint (e.g., compensation amount) on post-complaint satisfaction and customer behavior (e.g., Gilly and Gelb 1982). Moreover, early research establishes that postcomplaint satisfaction fosters positive customer behavior, that is, it increases repurchase intention (e.g., Gilly 1987) and positive word-of-mouth communication (positive WOM; e.g., TARP 1981). Starting with Goodwin and Ross (1989), later research builds on the justice theory to explain the occurrence of post-complaint satisfaction. It is argued and empirically shown that justice perceptions (distributive, procedural, and interactional justice) completely mediate the relationship between organizational responses and post-complaint satisfaction (Karande, Magnini, and Tam 2007; Maxham III and Netemeyer 2003; Smith, Bolton, and Wagner 1999).

Although the sequence of relationships-“organizational responses $\rightarrow$ justice perceptions $\rightarrow$ post-complaint satisfaction $\rightarrow$ customer behavior" - is well established, existing research suffers from a number of drawbacks, which require accumulated empirical research. First, extant studies cover only some of the relevant constructs (e.g., Liao 2007; Maxham III and Netemeyer 2002; Smith, Bolton, and Wagner 1999) instead of conjointly analyzing the full range of relationships in an overall model. Second, organizational responses and justice perceptions are not always clearly distinguished (Davidow 2003a). Third, with respect to post-complaint satisfaction, most researchers either use transaction-specific satisfaction, that is, satisfaction with handling the problem (e.g., Tax, Brown, and Chandrashekaran 1998) or cumulative satisfaction, that is, overall satisfaction with the organization (e.g., Varela-Neira, Vázquez-Casielles, and Iglesias-Argüelles 2008) or service (e.g., Worsfold, Worsfold, and Bradley 2007). Only a few studies address both constructs (e.g., Homburg and Fürst 2005; Maxham III and Netemeyer 2002). Fourth, empirical findings are contradictory. These inconsistencies refer to the

\footnotetext{
'Department of Marketing, Faculty of Economics, Ilmenau University of Technology, Ilmenau, Germany

\section{Corresponding Author:}

Holger Roschk, Department of Marketing, Faculty of Economics, Ilmenau University of Technology, P.O. Box 1005 65, 98684 IImenau, Germany

Email: holger.roschk@tu-ilmenau.de
} 


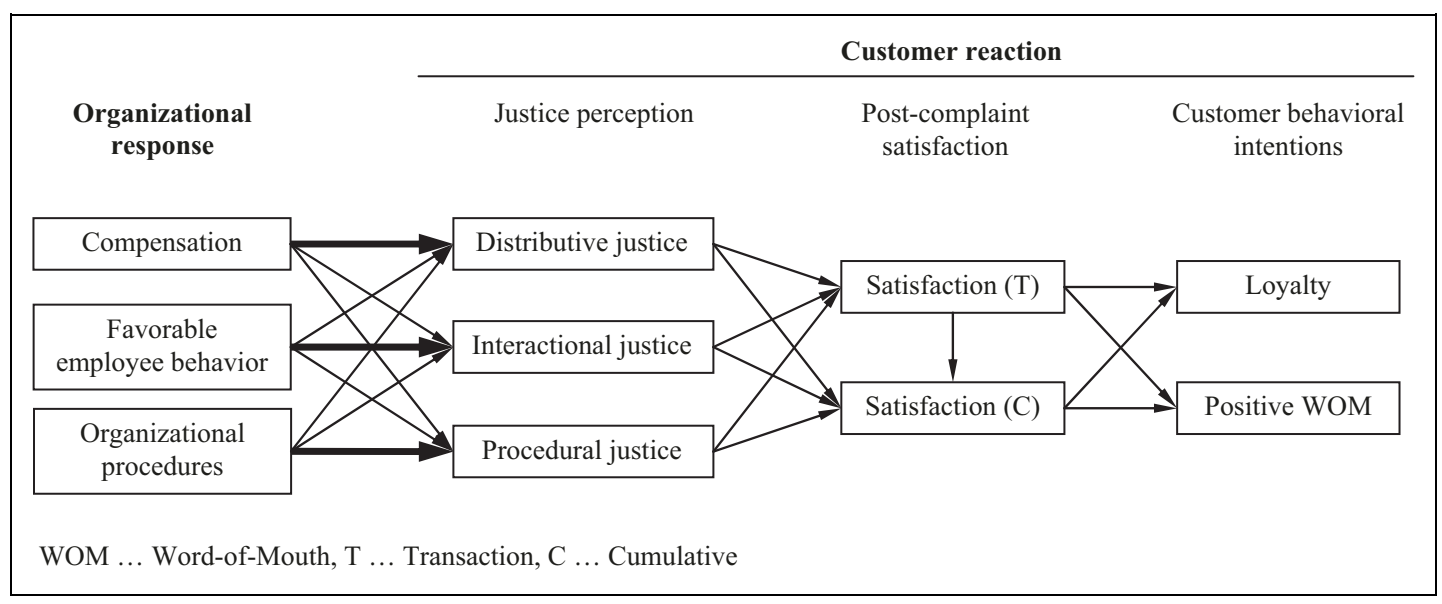

Figure I. Meta-analytic framework for post-complaint behavior.

relationship between organizational responses and justice perceptions. For instance, Smith, Bolton, and Wagner (1999) as well as McCollough, Berry, and Yadav (2000) report a significant positive effect of compensation on interactional justice, whereas Blodgett and Tax (1993) do not find support for this effect. Similarly, the importance of different justice dimensions remains unclear. For example, many studies show that distributive justice is the most important determinant of postcomplaint satisfaction (e.g., Homburg and Fürst 2005; Patterson, Cowley, and Prasongsukarn 2006; Smith, Bolton, and Wagner 1999), whereas others find that distributive justice has a weaker impact than procedural and/or interactional justice on post-complaint satisfaction (e.g., Maxham III and Netemeyer 2002; Tax, Brown, and Chandrashekaran 1998; Voorhees and Brady 2005).

Two attempts have been made to consolidate empirical findings: a review by Davidow (2003a) and a meta-analysis by Orsingher, Valentini, and de Angelis (2010). Davidow's (2003a) review is qualitative in nature and does not allow for empirical hypothesis testing. Moreover, it neither accounts for justice perceptions as separate model elements nor distinguishes between transaction-specific satisfaction and cumulative satisfaction. Orsingher, Valentini, and de Angelis (2010) do not integrate organizational responses. Further, they consider transaction-specific satisfaction to be the only antecedent to cumulative satisfaction, although single studies show significant direct effects of the justice dimensions on cumulative satisfaction (e.g., Davidow 2003b; Maxham III and Netemeyer 2002). Finally, although the authors include several moderators (study characteristics and societal culture), the moderator analysis for study characteristics is limited to accumulated relationship strength, which does not show to what extent single model relationships are strengthened or weakened by each moderator. Hence, the foregoing issues mainly remain unresolved. The current research aims to fill this void by embarking on a meta-analysis of the post-complaint literature using the framework shown in Figure 1.

This research makes three contributions to the literature. First, it examines the whole causal chain of post-complaint behavior across single studies, that is, organizational responses $\rightarrow$ justice perceptions $\rightarrow$ post-complaint satisfaction $\rightarrow$ customer behavior. Here, we clearly distinguish between organizational responses and perceptions of these responses. This approach improves the nomological validity of the constructs and, for the first time, provides an empirically tested overall model that can be used as a platform for future research. Second, this research assesses and compares the accumulated effects of each justice dimension on both transaction-specific satisfaction and cumulative satisfaction. Third, it examines the idiosyncratic effects of study characteristics (e.g., student sample vs. nonstudent sample) on single model relationships.

The study also has important managerial implications. It enables practitioners to assess the effectiveness of different organizational responses on each justice dimension. Moreover, service organizations learn how each justice dimension affects satisfaction with the given service encounter (i.e., transactionspecific satisfaction) and with the organization in general (i.e., cumulative satisfaction) and how these satisfaction judgments affect customer behavioral intentions (i.e., repurchase and positive WOM).

\section{Conceptual Framework}

Figure 1 shows the meta-analytic framework of this study, which is based on theory as well as on prior empirical findings. We include those constructs that are prominently analyzed and most important for this research stream. Prior research also examines additional constructs like trust (e.g., Kau and Loh 2006) and emotions (e.g., Chebat and Slusarczyk 2005), but we exclude them because they are only addressed in a few studies, and their position in the nomological network remains unclear. Tax, Brown, and Chandrashekaran (1998) and Kau and Loh (2006) place trust in the same position as behavioral intentions, whereas Kim, Kim, and Kim (2009) consider trust to be a partial mediator between post-complaint satisfaction and behavioral intentions. In a similar vein, del Río-Lanza, Vázquez-Casielles, and Díaz-Martín (2009) and Schoefer (2008) consider emotions as antecedents of post-complaint 


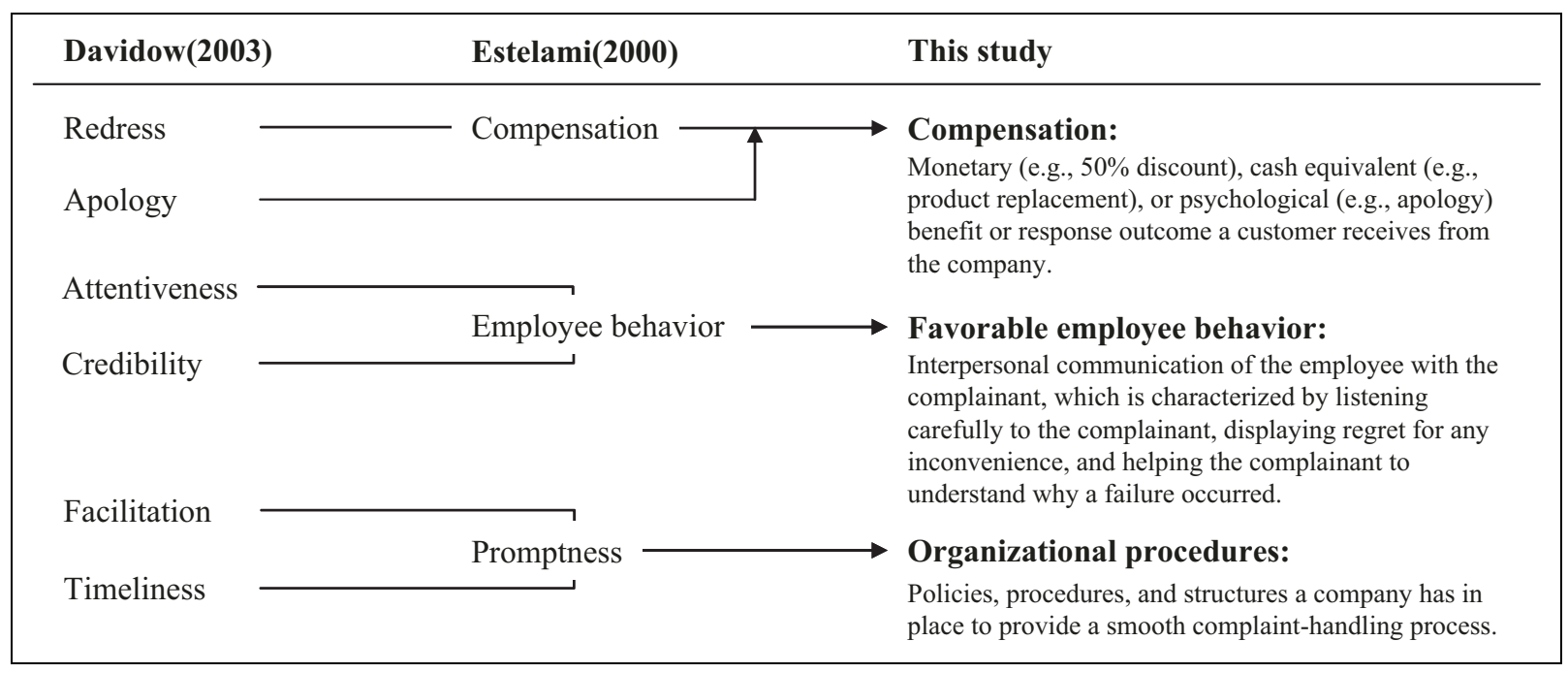

Figure 2. Description of organizational responses.

satisfaction, whereas DeWitt, Nguyen, and Marshall (2008) and Chebat and Slusarczyk (2005) use emotions, in lieu of post-complaint satisfaction, as mediators between justice perceptions and behavioral intentions.

\section{Organizational Responses}

Organizational responses are the initial reactions by a company in response to a complaint. They represent "the actual action itself taken by the organization" (Davidow 2003a, p. 232). As illustrated in Figure 2, organizational responses to complaints can be grouped into six (Davidow 2000, 2003a) or three categories (Estelami 2000). Although six categories encompass a broader spectrum, we draw on the three-partite classification by Estelami (2000) for two reasons. First, all three dimensions represent higher order factors of varied organizational responses. Second, not all six organizational responses have empirical relationships with every other construct in prior studies, whereas this condition is met when the three categories are used.

According to Estelami (2000), compensation refers to refunds, replacements, and/or discounts, which organizations provide to complainants. As such, compensation represents a tangible benefit in the form of a monetary or cash-equivalent remuneration. Similarly, Davidow $(2000,2003 a)$ uses the term "redress," which he describes as a benefit or response outcome that the organization provides to address a customer complaint. Such a benefit may involve more than just the purchase price and may cover additional costs of the failure (e.g., compensation of extra travel expenses). In a broader sense, however, compensation also comprises intangible response outcomes that can be considered to be psychological compensation. This is because a service failure often entails social loss (e.g., loss of face and threat of self-esteem). Social loss can be compensated by an apology (e.g., displaying regret for a failure), which is an intangible response outcome that helps restore social equity and redistribute esteem (Tax, Brown, and Chandrashekaran 1998). Hence, in line with others (e.g., Hess, Ganesan, and Klein 2003; Mattila and Patterson 2004), we consider apology as a form of compensation.

Employee behavior is described as empathic, friendly, responsible, careful, and informative behavior of the service person (Estelami 2000). For the sake of clarity, the term favorable employee behavior is used to indicate the positive valence of this construct. In Davidow's (2000, 2003a) framework, favorable employee behavior covers the interpersonal aspect of complaint handling by embracing attentiveness (i.e., listening carefully) and credibility (i.e., explaining the problem).

Promptness is described as an immediate and easy handling of complaint (Estelami 2000). This description encompasses facilitation and timeliness, both of which refer to the ability of organizations to control complaint-handling processes in an efficient and straightforward manner. This organizational response, however, is renamed "organizational procedures," which better fits the content of both categories, whereas the term "promptness" is rather an alias of timeliness.

\section{Justice Perceptions}

Justice perceptions are the individual subjective assessments of organizational responses (Smith, Bolton, and Wagner 1999). The distinction between the actual action taken by the company (organizational response) and the following subjective evaluation of that response by the complainant (justice perception) is crucial because perceptions are a subjective, often biased, interpretation of reality that, rather than actual events, account for individual behavior (Griffin and Ross 1991).

Justice theory is used in more recent studies, which provide evidence that customers, who perceive the organizational response to a complaint as fair, display higher levels of 
post-complaint satisfaction than those who perceive the response as unfair (Maxham III and Netemeyer 2002; Patterson, Cowley, and Prasongsukarn 2006; Smith, Bolton, and Wagner 1999). Fairness is perceived when the ratio of an individual's outputs (benefits) to inputs (financial and nonfinancial efforts) is balanced with the ratio of the other party (Adams 1965).

While early studies on post-complaint behavior center on fairness in general (e.g., Blodgett, Granbois, and Walters 1993; Goodwin and Ross 1989), it is now agreed that customers perceive fairness in three dimensions. Distributive justice refers to the perceived outcome of a decision or exchange. It embraces the perceived allocation of organizational resources in response to a complaint, that is, the apparent subjective benefit customers receive to offset the inconvenience resulting from a company's failure (Smith, Bolton, and Wagner 1999). Procedural justice refers to how the complainant perceives the means of decision making and conflict resolution used by the organization (Lind and Tyler 1988; Thibaut and Walker 1975). A complaint procedure is considered fair when it is allegedly "easy to access, provides the complainant with some control over the disposition, is flexible, and is concluded in a convenient and timely manner" (Tax, Brown, and Chandrashekaran 1998, p. 62). Interactional justice refers to how customers perceive the way they are treated (Bies and Shapiro 1987). Treatment is perceived as fair when complainants assume that information is exchanged and that outcomes are communicated in a polite and respectful manner (Patterson, Cowley, and Prasongsukarn 2006). ${ }^{1}$

The distinctness of the three justice dimensions has recently been called into question. Davidow (2003b) and Liao (2007) report on high correlations between the justice dimensions. Subsequently, Liao models perceived justice as a higher order latent variable in a confirmatory factor analysis (CFA) using this construct as a single predictor of post-complaint satisfaction. Similarly, DeWitt, Nguyen, and Marshall (2008) include the justice dimensions in one latent variable in their CFA, arguing that customers use a compensatory model when forming an overall perception of justice. A possible reason for the poor discriminant validity is that consumers are unable to clearly distinguish between, for instance, a favorable outcome (distributive justice) and respectful treatment (interactional justice): they might consider a positive complaint outcome as a friendly act of the organization. Similarly, halo effects could prevent consumers from differentiating the perceptions correctly. The goal of this study, however, is to determine whether the three justice dimensions have idiosyncratic antecedents and consequences that aid in deriving implications for marketing practitioners. Hence, they are modeled as separate constructs.

Research provides evidence that each organizational response may affect the three justice dimensions (Homburg and Fürst 2005; Smith, Bolton, and Wagner 1999). From a contentanalytic point of view, it seems reasonable that compensation has the strongest impact on distributive justice, favorable employee behavior on interactional justice, and organizational procedures on procedural justice (Blodgett, Hill, and Tax 1997;
McCollough, Berry, and Yadav 2000). The thicker arrows in Figure 1 illustrate this contention.

More recently, it is found that justice perceptions not only foster post-complaint satisfaction but also that the three fairness dimensions completely mediate the relationship between organizational responses and post-complaint satisfaction (e.g., Karande, Magnini, and Tam 2007; Maxham III and Netemeyer 2003). In other words, a fair perception of organizational responses is an antecedent to and a necessary condition for post-complaint satisfaction.

\section{Post-Complaint Satisfaction}

The occurrence of post-complaint satisfaction can be explained by the disconfirmation paradigm (e.g., McCollough, Berry, and Yadav 2000). That is, satisfaction is the result of a comparison judgment between expected and actual performance (Oliver 1980). Based on the object of judgment, the literature distinguishes between two satisfaction constructs. Transaction-specific satisfaction refers to the judgment of a single observation or transaction (Oliver 1997). It refers to a particular experience with an organization (Olsen and Johnson 2003), such as a single service encounter or product purchase. Cumulative satisfaction extends the scope of judgment to the accumulated experiences of consumers. It refers to the overall performance of a product or service provider to date (Johnson, Anderson, and Fornell 1995). Hence, cumulative satisfaction entails a condensed judgment of a broader spectrum of experiences, which leads to a more abstract level of evaluation than does transaction-specific satisfaction (Oliver 1997).

Both constructs are implicitly used for conceptualizing postcomplaint satisfaction. Transaction-specific satisfaction is usually referred to as "satisfaction with complaint handling" (Tax, Brown, and Chandrashekaran 1998) or "satisfaction with recovery" (Maxham III and Netemeyer 2003). In the following, we define it as the judgment of a particular complainthandling episode after product or service failure. A typical (reverse-coded) measurement item is "I am not satisfied with [firm name's] handling of this particular problem" (Maxham III and Netemeyer 2002, p. 252).

Other post-complaint researchers conceptualize postcomplaint satisfaction as an overall assessment of a product or service (e.g., Worsfold, Worsfold, and Bradley 2007) or of an entire organization (e.g., McColl-Kennedy, Daus, and Sparks 2003), which customers experience after complaint handling. This definition corresponds with the concept of cumulative satisfaction. A sample item is "I am satisfied with my overall experience with this firm" (Maxham III and Netemeyer 2003, p. 60). Given the additive nature of this concept, cumulative post-complaint satisfaction not only takes into account the judgment of a particular recovery effort but also covers the experiences with the organization prior to these recovery efforts. Hence, we predict that transaction-specific satisfaction fosters, but does not completely explain, cumulative satisfaction (Maxham III and Netemeyer 2002). 
Current research provides evidence that the three justice dimensions contribute to the explanation of post-complaint satisfaction. It is also demonstrated that post-complaint satisfaction partly mediates the relationship between justice perceptions and customer behavioral intentions (Maxham III and Netemeyer 2002) and completely mediates the relationship between organizational responses and customer behavioral intentions (Wirtz and Mattila 2004). However, the effect size of the three justice dimensions on satisfaction fluctuates remarkably (Patterson, Cowley, and Prasongsukarn 2006; Tax, Brown, and Chandrashekaran 1998; Weun, Beatty, and Jones 2004). This might be because some studies draw on transaction-specific post-complaint satisfaction, while others draw on cumulative post-complaint satisfaction (Maxham III and Netemeyer 2002). Hence, we consider the two constructs as separate model elements.

\section{Behavioral Intentions}

Customer behavior is usually measured on an intentional level. The two most important constructs are customer loyalty and positive WOM (Gilly and Gelb 1982; TARP 1981). Loyalty refers to a customer's intention to continue to do business with an organization (e.g., de Ruyter and Wetzels 2000). It is likewise referred to as repurchase intention (e.g., Blodgett, Hill, and Tax 1997). We also subsume commitment under loyalty because the operationalization of commitment in pertinent studies (e.g., "I wanted to continue dealing with this organization;" Tax, Brown, and Chandrashekaran 1998, p. 74) is identical to that of loyalty.

WOM communication comprises both the likelihood of spreading information on a company and the valence of this information (Davidow 2000, 2003a). In the post-complaint literature, likelihood and valence are usually combined in one construct yielding the likelihood of positive WOM and the likelihood of negative WOM, respectively (e.g., Blodgett, Hill, and Tax 1997; Maxham III and Netemeyer 2003). For the purpose of simplicity, we use the terms positive WOM and negative WOM. Positive WOM then is the likelihood of consumers spreading favorable information about a company, which includes recommending the company and its products and services (Maxham III and Netemeyer 2003). Negative WOM refers to the likelihood of consumers to spread unfavorable information about a company, which includes advising against the company and its products or services (Blodgett, Hill, and Tax 1997). Some researchers consider positive and negative WOM to be opposite ends of one and the same continuum (e.g., Kau and Loh 2006). Although this may hold true for the mere valence of a consumer's reference, the likelihood of both WOM types is not necessarily negatively interdependent: One may (be likely to) tell positive as well as negative things about a company (Blodgett and Anderson 2000).

We only consider positive WOM because after service failure, positive WOM (as opposed to negative WOM) can be clearly identified as following a complaint and subsequent recovery efforts. Blodgett and Anderson (2000) show that post-failure positive WOM tends to result from effective recovery efforts; it does not occur when customers do not complain and, subsequently, do not initiate failure reparation. This is because failure persistence and the lack of service recovery efforts prevent customers from recommending the organization. Post-failure negative WOM, on the contrary, may arise prior to - or in lieu of - a complaint as well as subsequent to ineffective recovery efforts after a complaint (Blodgett and Anderson 2000). In the first instance, negative WOM cannot be attributed to (ineffective) recovery efforts because there is no complaint and no subsequent organizational response. As extant studies on negative WOM hardly distinguish between the two instances, we omit negative WOM to minimize bias due to model misspecification.

Both customer loyalty and positive WOM are well established as major satisfaction outcomes (Oliver 1997). Applied to post-complaint behavior, it is shown that customers who are satisfied with complaint handling engage in positive WOM and are more loyal than customers who are dissatisfied with complaint handling. This holds true for transaction-specific satisfaction (Weun, Beatty, and Jones 2004; Worsfold, Worsfold, and Bradley 2007) and for cumulative satisfaction (Davidow 2000; Spreng, Harrell, and Mackoy 1995).

\section{Method}

\section{Literature Search}

We searched Business Source Complete (Ebsco), Science Direct, Emerald Management Xtra, ABI/Inform, and PsycINFO databases, as well as the Social Science Citation Index, for empirical studies reporting on one or more relationships between any pair of constructs specified in Figure 1. In addition, we e-mailed researchers requesting them to provide additional statistics in cases where no effect size could be calculated. The literature search covered the period 1980 to June 2009 and generated 142 empirical articles. Of these, 55 articles could not be included because they did not report enough statistics to estimate or approximate correlation coefficients. A complete list of the remaining 87 studies is available on request from the authors. The inclusion rate of $61.3 \%$ was comparable with the rates reported in other meta-analyses in marketing (e.g., Kirca, Jayachandran, and Bearden 2005; Szymanski and Henard 2001). The 87 studies contained 95 independent samples with a total $N$ of 28,826 . A total of 477 effects were obtained with an average total $N$ per relationship of 3,667.

\section{Coding Procedure}

Two independent coders identified the relevant relationships based on the construct operationalizations. In most cases, the operationalization of study constructs corresponded to construct definition of Figure 1. Three issues required particular attention. First, ambiguous constructs were organized into the category reflecting the majority of items measured (see Geyskens, Steenkamp, and Kumar 1999). In case of equal numbers of items, the ambiguous construct was coded as representing two constructs. 
Second, we had defined positive WOM as the likelihood of spreading favorable information about a company. Hence, we only included constructs that explicitly indicated both likelihood and positive valence (e.g., "How likely are you to spread positive word of mouth about the company?"). We relieved constructs with items like "While talking about my complaint, I emphasize how well the company took care of it" because they measure mere valence rather than likelihood.

A third issue was experimental studies. Researchers usually manipulated the level of an organizational response (e.g., prompt vs. slow complaint handling) and considered the manipulated variables either as organizational response, such as promptness (Type 1 studies; e.g., Liao 2007), or as justice perception, such as procedural justice (Type 2 studies; e.g., Blodgett, Hill, and Tax 1997). This inconsistency occurs because it is virtually impossible to manipulate justice perceptions directly (and no study did so). Hence, manipulating the level of an organizational response is a standard experimental design to trigger justice perceptions. To handle this inconsistency, we took the liberty of coding the Type 2 studies as organizational response (Davidow 2003a). We did so because a meta-analysis should depict the state of research based on what the actual operationalization is based on (Lipsey and Wilson 2001), which, for both study types, is the actual organizational complaint response.

When the described coding procedures were applied, the intercoder reliability according to Perreault and Leigh (1989) was .93 , which exceeded the required threshold of .8. Inconsistencies were resolved through discussion.

\section{Calculation of Effect Size}

We used the correlation coefficient to calculate the pairwise effect size estimates between the variables in the framework (e.g., Kirca, Jayachandran, and Bearden 2005; Palmatier et al. 2006). Missing correlation coefficients were approximated through other statistical data (e.g., Student's $t, F$ ratios, $\chi^{2}$, $\beta$ coefficients) by means of the formulas suggested by Peterson and Brown (2005) and Glass, McGaw, and Smith (1981). Some studies provided more than one correlation for the same relationship by analyzing different subsamples. Such dependent effects were averaged, which prevented multiple counts of dependent effect size estimates and subsequent biased results (e.g., Palmatier et al. 2006).

To correct for measurement error, the correlations were adjusted for reliability (Hunter and Schmidt 2004). Some studies used single-item measures or did not report on reliabilities. In such cases, the mean reliability for the respective construct across all studies was used as an approximation (Kirca, Jayachandran, and Bearden 2005). Adjustment for sampling error was made by weighting the individual reliabilityadjusted correlation coefficients by sample size. The mean of these weighted coefficients yielded pooled correlation coefficients (Hunter, Schmidt, and Jackson 1982). ${ }^{2}$

\section{Course of Analysis}

For each significant relationship, we provided a series of univariate statistics including fail-safe- $n$ (Rosenthal 1979), $\chi^{2}$-statistics as well as the sample error variance (Hunter, Schmidt, and Jackson 1982) and the $95 \%$ confidence intervals (Schmidt and Hunter 1999). Then, a path model was analyzed using the Structural Equation Modeling (SEM) software AMOS 7.0 with the maximum likelihood estimation. Model inputs were the pooled correlation coefficients (see Table 1) as well as median sample size ( $N=241$; Kirca, Jayachandran, and Bearden 2005). As there is no empirical evidence for correlations among the organizational responses, correlations of .0 were assumed between them. Further, there were high correlations between the justice dimensions and their error terms. Hence, we allowed the error terms to correlate, which is legitimate under two conditions (Bagozzi 1983; Fornell 1983; Gerbing and Anderson 1984). First, there has to be theoretical and/ or empirical evidence for the existence of a second-order factor. Indeed, recent arguments and empirical findings call the discriminant validity of the three justice dimensions into question (DeWitt, Nguyen, and Marshall 2008; Liao 2007). Second, adding correlated residuals must not significantly alter the structural parameter estimates. In our model, the path coefficients remained stable.

Prior to model calculation, we removed outliers, which may cause inconsistencies in the correlation matrix (Lipsey and Wilson 2001). We proceeded as follows: the correlation coefficients that exhibited values higher than three times the standard error of the respective distribution were identified. Then, those outliers that were flawed by methodological drawbacks (e.g., poor content validity of a construct and confounding effects of extraneous variables) were removed. In all, $5.5 \%$ of the correlation data points were eliminated. Following the removal of outliers, path model estimation included four steps: estimation of path coefficients (including indirect effects and mediation analysis), relative effect analysis, estimation of competing models, and moderator analyses.

\section{Results \\ Univariate and Bivariate Results}

Table 1 shows the sample-weighted reliability-adjusted correlations $(r)$ between the model elements, the standard deviation $(S D), 95 \%$ confidence intervals $(\mathrm{CI})$, total sample size $(N)$, and number of observations $(k)$. All correlation coefficients are significant at $p<.01$, except for the relationship "favorable employee behavior $\rightarrow$ procedural justice." The average of correlations is .44 , ranging from .12 for "compensation $\rightarrow$ procedural justice" to .72 for "interactional justice $\rightarrow$ cumulative satisfaction." Table 1 also shows that the numbers of observations between organizational responses and justice dimensions are relatively low.

Table 2 provides additional statistics for the model relationships. Overall, fail-safe- $n$ is 7,051. Hence, the mean number of discarded null results that would be necessary to bring the 


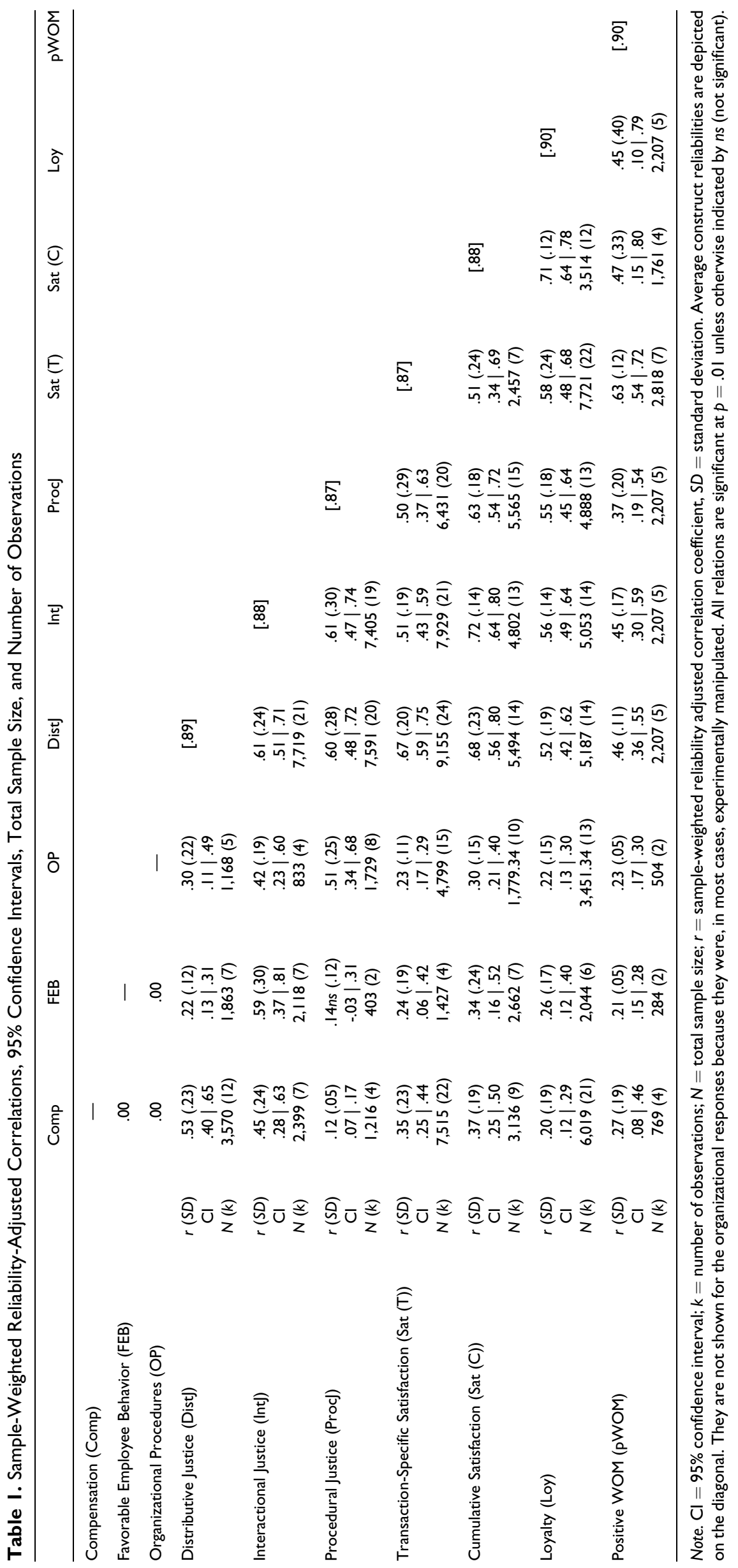


Table 2. Fail-Safe-n, $\chi^{2}$ Values, Ratio of Sampling Error Variance to Observed Variance

\begin{tabular}{|c|c|c|c|c|c|c|c|c|c|c|c|}
\hline & & Comp & FEB & OP & Dist] & Int & Proc & Sat $(T)$ & Sat $(C)$ & Loy & pWOM \\
\hline Favorable Employee Behavior (FEB) & & NA & - & & & & & & & & \\
\hline Organizational Procedures (OP) & & NA & NA & - & & & & & & & \\
\hline Distributive Justice (Dist]) & $\begin{array}{l}\text { FSN } \\
\chi^{2} \\
s_{e}^{2} / s_{r}^{2}\end{array}$ & $\begin{array}{c}3,439 \\
247.5 \\
4 \%\end{array}$ & $\begin{array}{l}156 \\
25.7 \\
27 \%\end{array}$ & $\begin{array}{c}160 \\
51.0 \\
9 \%\end{array}$ & {$[.89]$} & & & & & & \\
\hline Interactional Justice $(\ln t)$ & $\begin{array}{l}\text { FSN } \\
\chi^{2} \\
s_{e}^{2} / s_{r}^{2}\end{array}$ & $\begin{array}{c}797 \\
\mid 44.4 \\
4 \%\end{array}$ & $\begin{array}{c}3,020 \\
343.9 \\
2 \%\end{array}$ & $\begin{array}{c}89 \\
31.9 \\
12 \%\end{array}$ & $\begin{array}{c}2,6808 \\
712.4 \\
3 \%\end{array}$ & {$[.88]$} & & & & & \\
\hline Procedural Justice (Proc J) & $\begin{array}{l}\text { FSN } \\
\chi^{2} \\
s_{e}^{2} / s_{r}^{2}\end{array}$ & $\begin{array}{l}10 \\
2.7 \\
-\end{array}$ & $\begin{array}{l}- \\
5.5 \\
37 \%\end{array}$ & $\begin{array}{c}1,629 \\
\mid 48.5 \\
5 \%\end{array}$ & $\begin{array}{c}27,835 \\
926.7 \\
2 \%\end{array}$ & $\begin{array}{c}27,033 \\
989.9 \\
2 \%\end{array}$ & {$[.87]$} & & & & \\
\hline Cumulative Satisfaction (Sat (C)) & $\begin{array}{l}\text { FSN } \\
\chi^{2} \\
s_{e}^{2} / s_{r}^{2}\end{array}$ & $\begin{array}{c}1,018 \\
142.4 \\
7 \%\end{array}$ & $\begin{array}{c}911 \\
175.3 \\
4 \%\end{array}$ & $\begin{array}{l}452 \\
33.5 \\
24 \%\end{array}$ & $\begin{array}{c}25,291 \\
627.3 \\
2 \%\end{array}$ & $\begin{array}{c}19,407 \\
315.3 \\
6 \%\end{array}$ & $\begin{array}{c}17,113 \\
315.0 \\
5 \%\end{array}$ & $\begin{array}{c}1,928 \\
131.6 \\
4 \%\end{array}$ & {$[.88]$} & & \\
\hline Loyalty (Loy) & $\begin{array}{l}\text { FSN } \\
\chi^{2} \\
s_{e}^{2} / s_{r}^{2}\end{array}$ & $\begin{array}{c}1,770 \\
205.3 \\
10 \%\end{array}$ & $\begin{array}{c}463 \\
65.0 \\
9 \%\end{array}$ & $\begin{array}{l}609 \\
71.3 \\
17 \%\end{array}$ & $\begin{array}{c}6,566 \\
259.2 \\
5 \%\end{array}$ & $\begin{array}{c}8,00 \mid \\
|49 .| \\
9 \%\end{array}$ & $\begin{array}{c}6,143 \\
180.5 \\
6 \%\end{array}$ & $\begin{array}{c}23,042 \\
760.2 \\
3 \%\end{array}$ & $\begin{array}{c}9,632 \\
134.5 \\
11 \%\end{array}$ & {$[.90]$} & \\
\hline Positive WOM (pWOM) & $\begin{array}{l}\text { FSN } \\
\chi^{2} \\
s_{e}^{2} / s_{r}^{2}\end{array}$ & $\begin{array}{c}19 \\
29.9 \\
15 \%\end{array}$ & $\begin{array}{c}7 \\
0.6 \\
-\end{array}$ & $\begin{array}{l}14 \\
0.8 \\
-\end{array}$ & $\begin{array}{l}815 \\
30.7 \\
16 \%\end{array}$ & $\begin{array}{c}806 \\
65.8 \\
7 \%\end{array}$ & $\begin{array}{c}557 \\
89.9 \\
5 \%\end{array}$ & $\begin{array}{c}2,648 \\
66.3 \\
10 \%\end{array}$ & $\begin{array}{c}738 \\
226.2 \\
2 \%\end{array}$ & $\begin{array}{c}1,296 \\
403.2 \\
1 \%\end{array}$ & {$[.90]$} \\
\hline
\end{tabular}

Note. FSN $=$ fail-safe- $n$ (not calculated for insignificant relationships, indicated by a dotted line), $\chi^{2}=$ chi-square value $($ degrees of freedom $=k-1), s_{e}^{2} / s_{r}^{2}=$ ratio of sampling error variance to observed variance (not calculated for homogeneous relationships, indicated by a dotted line). Average construct reliabilities are depicted on the diagonal. They are not shown for the organizational responses because they were, in most cases, experimentally manipulated. NA $=$ not available.

relationships to nonsignificance is very large. Only 2 of the 41 fail-safe- $n$ values are low (favorable employee behavior $\rightarrow$ positive $\mathrm{WOM}=7$, compensation $\rightarrow$ procedural justice $=$ 10). Overall, the correlations were robust with regard to the file-drawer problem.

The $\chi^{2}$ values are significant in all but three relationships indicating heterogeneous relationships. However, significant $\chi^{2}$ values may also be due to large sample sizes and to the high power of this test even for trivial amounts of variation across studies (Hunter, Schmidt, and Jackson 1982). Moreover, $\chi^{2}$ values do not allow assessing whether the observed variance (i.e., heterogeneity) is due to the variation in population correlations or simply to sampling error. Hence, $s_{e}^{2} / s_{r}^{2}$ (sampling error variance divided by the observed variance of correlation coefficients) is also reported. Almost all $s_{e}^{2} / s_{r}^{2}$ values are well below $30 \%$. The values are particularly low for the relationships between justice perceptions and satisfaction constructs (i.e., $\leq 6 \%$ ). This indicates that the variation in the correlation coefficients seems to be due to moderator variables rather than to mere sampling error in these relationships.

\section{Path Model Estimation}

Estimation of path coefficients. Figure 3 shows the results of the path model estimation. The hypothesized structural model yields an excellent fit $\left(\chi^{2}[22]=29.670, p=.127\right.$, adjusted goodness of fit index $[\mathrm{AGFI}]=.942$, comparative fit index $[\mathrm{CFI}]=.995$, root mean square error of approximation $[$ RMSEA $]=.038)$. As expected, the error terms of the three justice dimensions are correlated to one another $(p<.001)$. The correlations range from .29 (distributive justice $\rightarrow$ interactional justice) to .55 (distributive justice $\rightarrow$ procedural justice) and .59 (interactional justice $\rightarrow$ procedural justice), respectively.

Of the 20 estimated path coefficients, 17 are significant at the .05 level. Contrary to expectations, three path coefficients are insignificant: "interactional justice $\rightarrow$ transaction-specific satisfaction" ( $\beta=.12, p=.067)$, "procedural justice $\rightarrow$ transaction-specific satisfaction" $(\beta=.11, p=.098)$, and "transaction-specific satisfaction $\rightarrow$ cumulative satisfaction" ( $\beta=.00, p=.942)$. Elimination of the insignificant paths does not increase the model fit significantly. Hence, the insignificant 


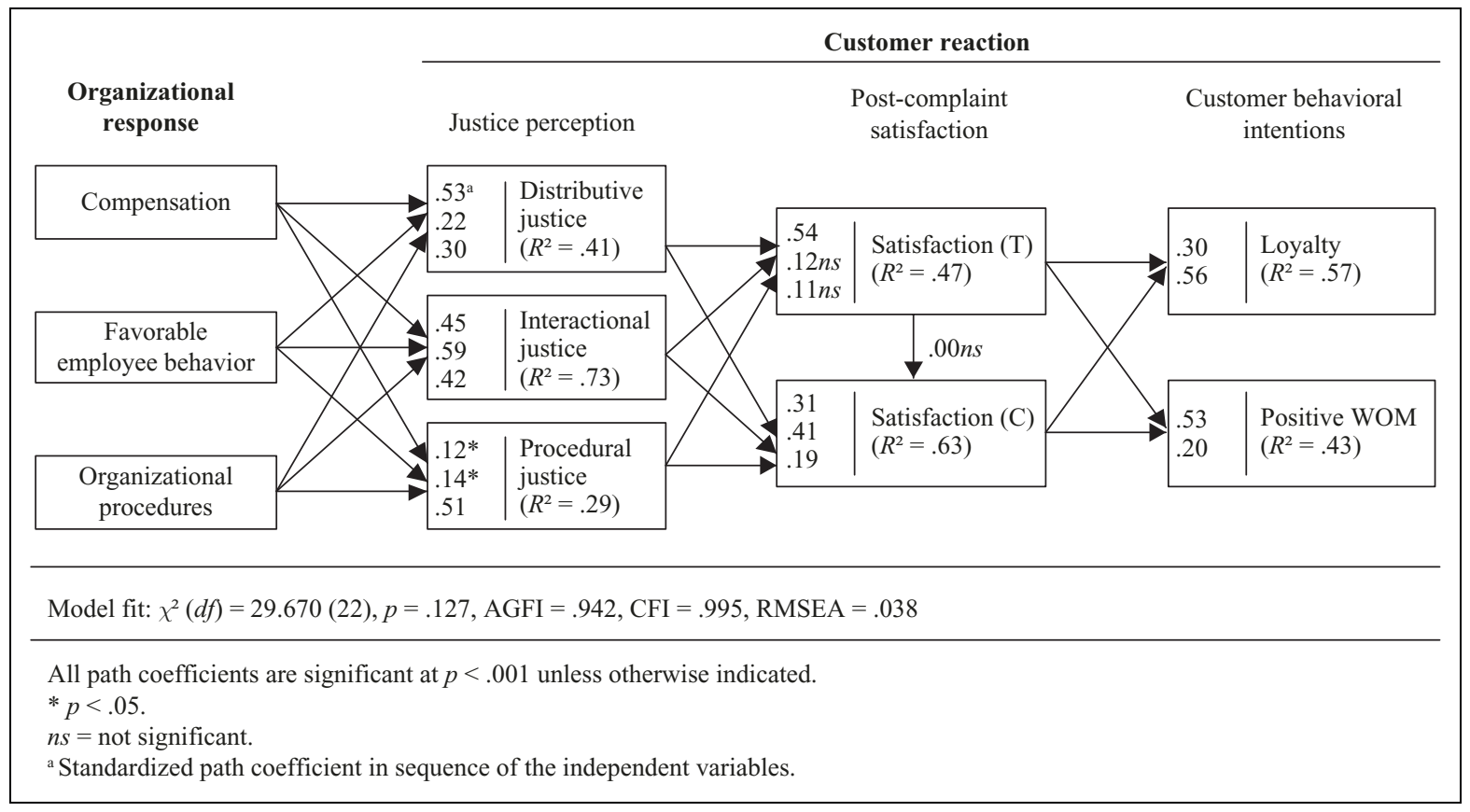

Figure 3. Model estimation results.

Note. $\mathrm{AGFI}=$ adjusted goodness of fit index; $\mathrm{CFI}=$ comparative fit index; RMSEA = root mean square error of approximation; WOM = word of mouth.

Table 3. Indirect Effects

\begin{tabular}{lccccccc}
\hline & Comp & FEB & OP & Dist] & Int & ProcJ & Sat (T) \\
\hline Satisfaction (T) & $.35^{\mathrm{a}}$ & .20 & .26 & & & & \\
Satisfaction (C) & .38 & .34 & .36 & .00 & .00 & .00 & \\
Loyalty & .31 & .25 & .28 & .33 & .27 & .14 & .00 \\
Positive WOM & .26 & .17 & .21 & .35 & .15 & .10 & .00 \\
\hline
\end{tabular}

${ }^{a}$ Standardized.

paths are retained. The hypothesized model accounts for $41 \%$ of the variance of distributive justice, $73 \%$ of interactional justice, $29 \%$ of procedural justice, $47 \%$ of transaction-specific satisfaction, $63 \%$ of cumulative satisfaction, $57 \%$ of loyalty, and $43 \%$ of positive WOM. $^{3}$ Hence, our theoretical model is largely validated.

Table 3 depicts indirect effects. Compensation (.35) has a larger influence on transaction-specific satisfaction than favorable employee behavior (.20) and organizational procedures (.26). This also applies to the three organizational responses' effect on positive WOM (.26 vs. .17 vs. .21). The indirect effect of the organizational responses on cumulative satisfaction (.38 vs. .34 vs. .36) and loyalty (.31 vs. .25 vs. .28) is more balanced. As for the indirect effects of the justice dimensions, distributive justice exerts a stronger effect on loyalty (.33) than interactional justice (.27) and procedural justice (.14). The same holds true for the three justice dimensions' effects on positive WOM (.35 vs. .15 vs. .10).

In addition, we test justice perceptions and post-complaint satisfaction as presumed mediators using the approach suggested by Baron and Kenny (1986). Mediation analysis for the justice perceptions reveals that the three justice perceptions fully mediate the relationship between organizational responses and cumulative satisfaction. However, only distributive justice mediates the relationship between organizational responses and transaction-specific satisfaction because the effects of interactional justice and procedural justice on transaction-specific satisfaction are insignificant (see Figure 3).

Mediation analysis for the satisfaction constructs reveals that cumulative satisfaction fully mediates the relationships between the justice dimensions and behavioral intentions, except for one counter claim because the relationship "procedural justice $\rightarrow$ positive WOM" is not significant. Again, due to the insignificant effects of interactional justice and procedural justice on transaction-specific satisfaction, transactionspecific satisfaction fully mediates only the relationship between distributive justice and behavioral intentions.

Relative effects analysis. To test which pair of model constructs has the largest relative effect, we use a nested models approach and $\chi^{2}$ difference test (see Maxham III and Netemeyer 2002). Table 4 depicts the results. Compensation exerts a stronger influence on distributive justice than organizational procedures $\left(\chi_{\text {diff }}^{2}[1]=10.454, p<.001\right)$ and favorable employee behavior $\left(\chi_{\text {diff }}^{2}[1]=18.844, p<.000\right)$. Favorable employee behavior has a larger impact on interactional justice than compensation $\left(\chi_{\text {diff }}^{2}[1]=8.193, p<.004\right)$ and organizational procedures $\left(\chi_{\text {diff }}^{2}[1]=12.521, p<.000\right)$. The effect of organizational procedures on procedural justice is greater than that of favorable employee behavior $\left(\chi_{\text {diff }}^{2}[1]=21.949\right.$, 
Table 4. Relative Effects Analysis Results

\begin{tabular}{|c|c|c|c|c|}
\hline Dependent Variable & \multicolumn{2}{|c|}{ Independent Variable } & $\chi \operatorname{diff}(d f=I)^{b}$ & $p$ \\
\hline Interactional Justice & Favorable Employee Behavior & $\begin{array}{l}\text { Compensation } \\
\text { Organizational Procedures }\end{array}$ & $\begin{array}{r}8.193 \\
12.52 \mid\end{array}$ & $\begin{array}{l}.004 \\
.000\end{array}$ \\
\hline Satisfaction $(T)$ & Distributive Justice & $\begin{array}{l}\text { Interactional Justice } \\
\text { Procedural Justice }\end{array}$ & $\begin{array}{l}15.065 \\
16.157\end{array}$ & $\begin{array}{l}.000 \\
.000\end{array}$ \\
\hline Satisfaction (C) & Interactional Justice & $\begin{array}{l}\text { Distributive Justice } \\
\text { Procedural Justice }\end{array}$ & $\begin{array}{l}1.207 \\
6.254\end{array}$ & $\begin{array}{l}.272 \\
.012\end{array}$ \\
\hline
\end{tabular}

${ }^{a}$ In terms of standardized path coefficient.

${ }^{\mathrm{b}} \chi^{2}$ value of the hypothesized model $=29.670(d f=22)$.

$p<.000)$ and compensation $\left(\chi_{\text {diff }}^{2}[1]=23.626, p<.000\right)$. Distributive justice is a more powerful predictor of transactionspecific satisfaction than interactional justice $\left(\chi_{\text {diff }}^{2}[1]=\right.$ $15.065, p<.000)$ and procedural justice $\left(\chi_{\text {diff }}^{2}[1]=16.157\right.$, $p<.000)$. Interactional justice and distributive justice exert the same effect on cumulative satisfaction $\left(\chi_{\text {diff }}^{2}[1]=1.207, p<\right.$ .272 ), and interactional justice has a higher influence than procedural justice $\left(\chi_{\text {diff }}^{2}[1]=6.254, p<.012\right)$. Cumulative satisfaction has a larger impact on loyalty than transaction-specific satisfaction $\left(\chi_{\text {diff }}^{2}[1]=8.831, p<.003\right)$. Transaction-specific satisfaction exhibits a stronger influence on positive WOM $\left(\chi_{\text {diff }}^{2}[1]=10.733, p<.001\right)$ than cumulative satisfaction. These results stress the importance of differentiating between transaction-specific and cumulative satisfaction because the strength of relationships with their antecedents and consequences differs significantly.

Competing models. We estimate competing models to assess the explanatory power of organizational responses, justice dimensions, and satisfaction constructs. For this purpose, we exclude the respective model element (e.g., justice dimensions) and allow direct paths between its antecedents (e.g., organizational responses) and consequences (e.g., satisfaction constructs). Each of the competing models is then compared with our theoretical model that includes the respective model element. We use Akaike's Information Criterion (AIC; Akaike 1987), change in variance explained of the dependent variables $\left(\Delta R^{2} ;\right.$ Bagozzi and Baumgartner 1996), and effect size ( $f^{2}$; Cohen 1988) as recommended for unnested models. We also report RMSEA values and $\chi^{2}$ to degrees of freedom ratio to assess model fit (see Table 5).

Compared with the hypothesized model, the AIC values decrease in three of the five competing models, indicating a better model fit. However, as the overall fit statistics of the competing models $\left(\chi^{2} / d f\right.$ and RMSEA) remain at about the same level as that in the hypothesized model (or become even worse), the lower AIC values can be attributed to reduced model complexity. Hence, we use $\Delta R^{2}$ and $f^{2}$ to assess competing models.

Excluding organizational responses (Model 1) substantially reduces $R^{2}$ values of distributive justice $\left(\Delta R^{2}=-.41, f^{2}=.69\right)$, interactional justice $\left(\Delta R^{2}=-.73, f^{2}=2.70\right)$, and procedural justice $\left(\Delta R^{2}=-.29, f^{2}=.41\right)$. Excluding the justice constructs (Model 2) leads to a substantial drop in the variance explained of transaction-specific satisfaction $\left(\Delta R^{2}=-.24, f^{2}=.45\right)$ and of cumulative satisfaction $\left(\Delta R^{2}=-.21, f^{2}=.57\right)$. It is important to note that in Model 2, when justice perceptions are omitted, the path from transaction-specific satisfaction to cumulative satisfaction becomes significant $(\beta=.30, p<.001)$.

Omitting transaction-specific satisfaction (Model 3) leads to a substantial decrease in the $R^{2}$ value of positive $\operatorname{WOM}\left(\Delta R^{2}=\right.$ $\left.-.21, f^{2}=.37\right)$ and to a moderate decrease in that of loyalty $\left(\Delta R^{2}=-.07, f^{2}=.16\right)$. Omitting cumulative satisfaction (Model 4) also has a weak negative impact on the $R^{2}$ value of positive $\operatorname{WOM}\left(\Delta R^{2}=-.03, f^{2}=.05\right)$ and a substantial negative effect on the $R^{2}$ value of loyalty $\left(\Delta R^{2}=-.23, f^{2}=.53\right)$. Excluding both satisfaction constructs (Model 5) yields substantially lower $R^{2}$ values of positive WOM $\left(\Delta R^{2}=-.18\right.$, $\left.f^{2}=.32\right)$ and of loyalty $\left(\Delta R^{2}=-.17, f^{2}=-.40\right)$.

Moderator analysis. To explain the heterogeneity of the effect sizes between justice perceptions and satisfaction constructs, we took five potential moderators into account, which have been addressed in other meta-analyses or reviews (e.g., Davidow 2003a; Geyskens, Steenkamp, and Kumar 1999). These are method (experiment vs. survey), subject (student vs. nonstudent), complaint type (monetary vs. nonmonetary complaint), industry type (service vs. non-service), and publication outlet (top tier vs. non-top tier). 
Table 5. Competing Models Results

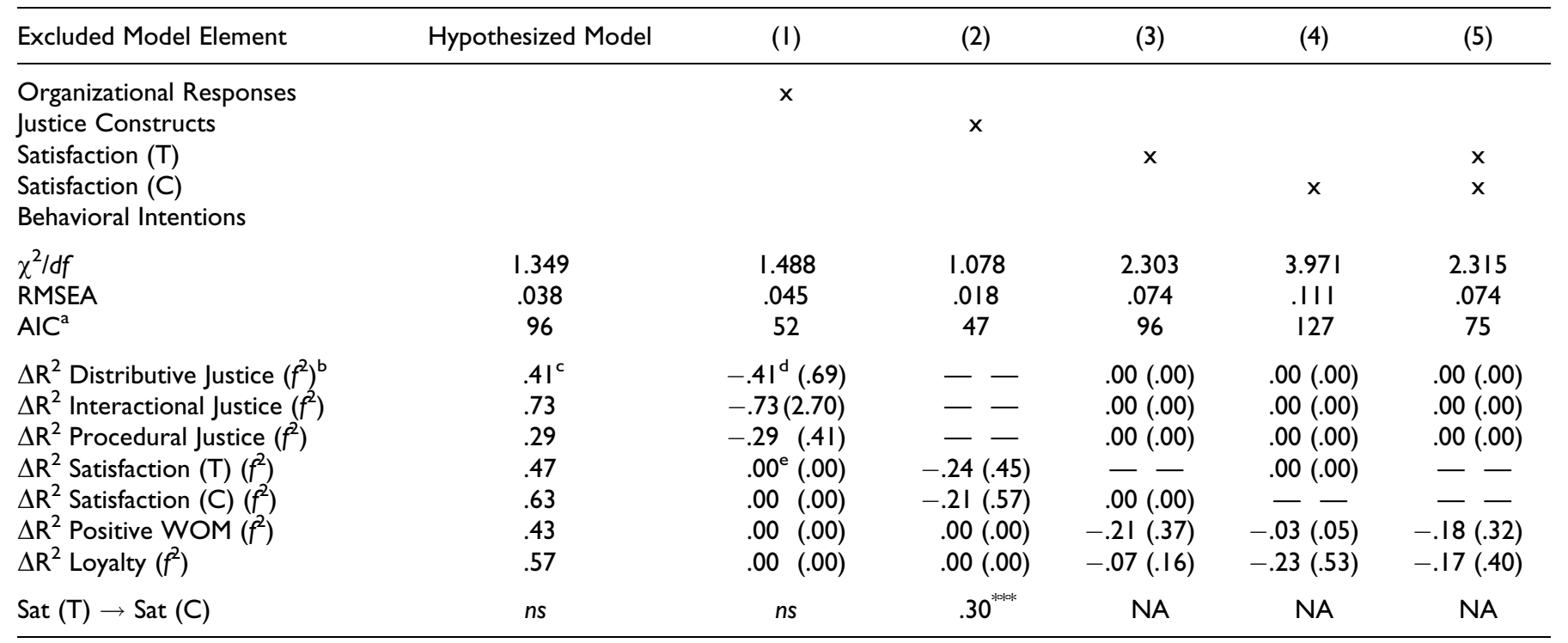

Note. $n s=$ relationship is not significant and therefore constrained to zero. NA = relationship between Sat (T) and Sat $(C)$ is not available for these models

${ }^{a}$ Akaike's Information Criterion.

${ }^{\mathrm{b}} f^{2}=\left(R_{\text {incl }}^{2}-R_{\text {excl }}^{2}\right) /\left(I-R_{\text {incl }}^{2}\right)$.

c $R^{2}$ values of the hypothesized model.

${ }^{d} \Delta R^{2}$ equals $R^{2}$ of the hyothesized model because Model I does not entai I any antecedents to the justice dimensions, which means that the $R^{2}$ of the justice dimensions are zero in Model I.

e These values are zero because they are not affected by excluding the respective model elements.

$p \leq .001$.

Of the 37 samples that could be used for moderator analysis, 12 were based on experimental and 25 on survey data. Subjects were students in 11 cases and nonstudents in 26 cases. Complaint type was reported less often, with seven cases being monetary (i.e., failure involves financial loss) and six cases being nonmonetary (i.e., failure involves no financial loss). There were 28 service settings, 4 non-service settings (i.e., consumer goods), and 5 mixed settings (e.g., both services and non-service). Eighteen samples were published in top-tier publications, whereas 19 samples originated from non-top-tier articles.

To test for moderation, we perform subgroup path analysis and use $\chi^{2}$ tests within a nested models approach. We estimate two satisfaction models one for transaction-specific satisfaction and one for cumulative satisfaction each with the three justice dimensions as independent variables (see Table 6).

For transaction-specific satisfaction, we obtain significant results for method, subject, and complaint type. Interactional justice has a larger impact in survey data $(\beta=.20)$ than in experiments $(\beta=.00)$ and procedural justice has a larger effect in nonstudent samples $(\beta=.16)$ than in student samples $(\beta=$ $.00)$. Complaint type significantly moderates the impact of distributive justice, interactional justice, and procedural justice on transaction-specific satisfaction. Distributive justice has a stronger impact when the complaint is monetary $(\beta=.58)$ than when it is nonmonetary $(\beta=.37)$. Interactional justice has a weaker impact (i.e., no impact) in a monetary $(\beta=.00)$ complaint situation than in a nonmonetary situation $(\beta=.25)$. Procedural justice is more important in a monetary complaint context $(\beta=.24)$ than in a nonmonetary complaint context $(\beta=.00)$. Industry type and publication outlet do not exert any moderating effect on the relationships between justice dimensions and transaction-specific satisfaction.

As for cumulative satisfaction, the method significantly moderates the impact of distributive and of procedural justice. Distributive justice has a stronger effect in experiments $(\beta=$ $.52)$ than in surveys $(\beta=.21)$, whereas procedural justice has a weaker influence in experiments $(\beta=.00)$ than in survey data $(\beta=.35)$. Furthermore, students significantly weigh distributive justice $(\beta=.46)$ more heavily than nonstudents $(\beta=$ .26 ), whereas the results for procedural justice are vice versa ( $\beta=.00$ vs. .29). With regard to industry type, interactional justice has a significant larger impact in service industries $(\beta=.46)$ than in non-service industries $(\beta=.25)$. Again, the publication outlet has no significant moderator effect.

We also checked for correlations among moderating variables. Crossing the moderator variables' frequencies and conducting $\chi^{2}$ tests, we find one significant relationship: student samples are more often used in experiments than in surveys, whereas nonstudent samples are more typical for surveys than for experiments $\left(C=.430, p=.004, \chi^{2}[1]=8.169\right)$. Hence, method and subject appear to be confounded.

\section{Discussion}

\section{Theoretical Implications}

The foregoing meta-analysis empirically validates the theoretical overall model of post-complaint behavior depicted in 


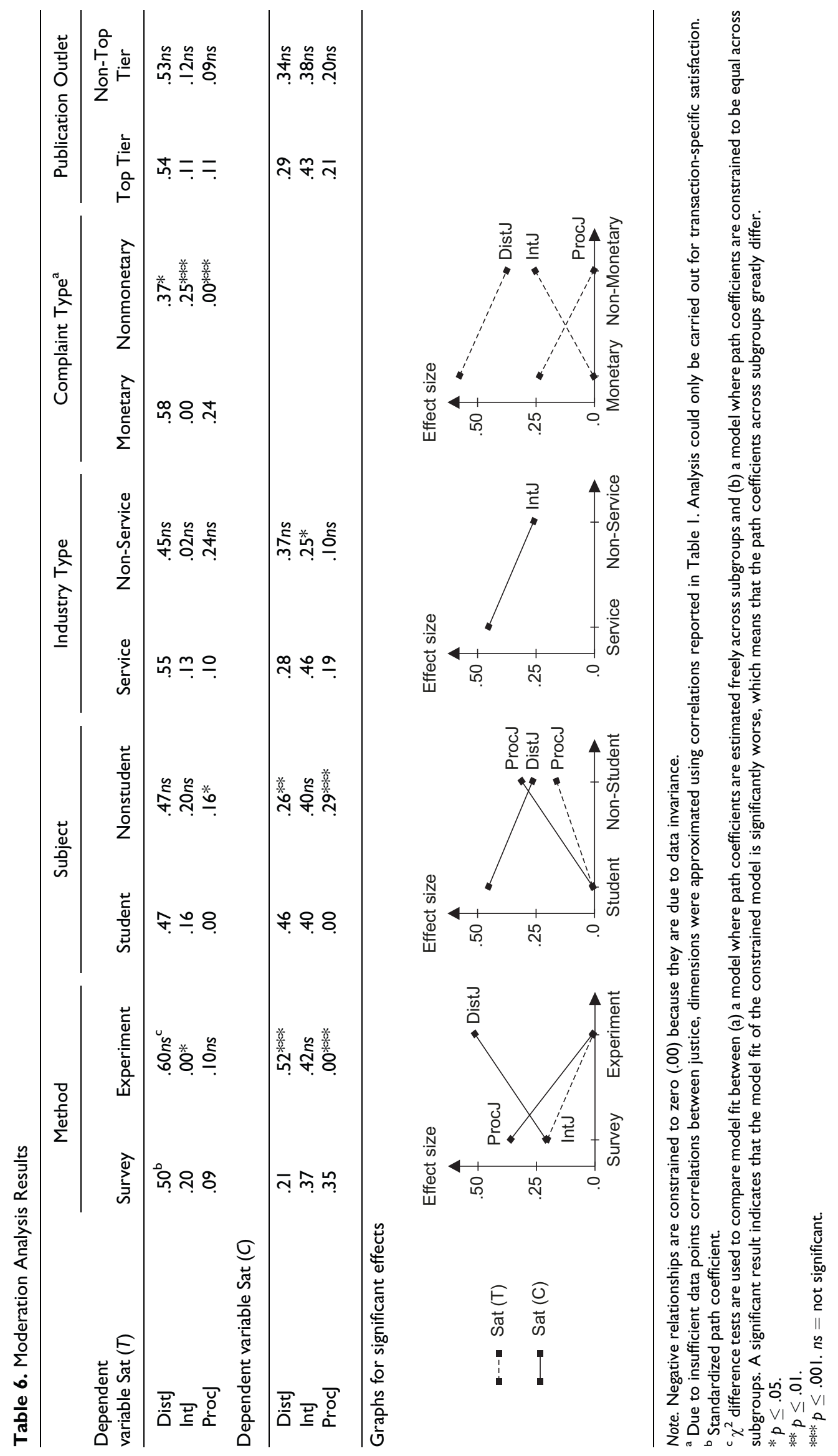


Figure 1. Our results enrich the findings of the meta-analysis by Orsingher, Valentini, and de Angelis (2010) and allow for new theoretical implications. We will discuss our findings separately for the model elements (organizational responses, justice perceptions, post-complaint satisfaction, and behavioral intentions) and for the moderators.

Organizational responses. While Orsingher, Valentini, and de Angelis (2010) do not include organizational responses, our research shows the idiosyncratic effects of the organizational responses on justice perceptions. Relative effect size analysis reveals that compensation is the most powerful determinant of distributive justice $(\gamma=.53)$, favorable employee behavior is the most powerful determinant of interactional justice $(\gamma=$ .59 ), and organizational procedures are the most powerful determinant of procedural justice $(\gamma=.51)$. Hence, the organizational responses are perceived as what they are: compensation as a fair outcome, favorable employee behavior as a fair interpersonal interaction, and organizational procedures as a fair complaint process. In addition, there are a number of-less strong-"cross-effects" (e.g., $\gamma=.22$ between favorable employee behavior and distributive justice), suggesting irradiations from each of the organizational responses on each of the justice dimensions.

The three organizational responses do not exhaustively explain the justice dimensions (distributive, $41 \%$; interactional, $73 \%$; and procedural, 29\%). In particular, the low values for distributive justice and procedural justice warrant further attention. Two factors may account for this result. First, we were forced to consolidate and subsume similar organizational responses (e.g., empathy and respect) under the same category (e.g., favorable employee behavior). In reality, though similar, these recovery efforts may explain idiosyncratic proportions of variance. Hence, considering them as distinct rather than as substitutes may better explain justice perceptions. Second, the type (e.g., refund and replacement) and the level of compensation (e.g., full vs. partial) examined in the single studies vary considerably (Mattila 2006; McCollough, Berry, and Yadav 2000; Webster and Sundaram 1998), and other research suggests that type and level of compensation affect customer responses (Mount and Mattila 2000; Smith, Bolton, and Wagner 1999).

Justice dimensions. The path model estimation and the relative effect size analysis show that the effect of distributive justice $(\beta=.54)$ on transaction-specific post-complaint satisfaction is larger than the effect of interactional justice ( $\beta=.12)$, whereas procedural justice $(\beta=.11)$ has the weakest impact. This finding is consistent with Orsingher, Valentini, and de Angelis (2010) who use the term satisfaction with complaint handling and report $\beta=.45$ for distributive justice, $\beta=.25$ for interactional justice, and $\beta=.09$ for procedural justice. The effect of procedural justice is negligible because most companies will not offer the consumer a deep insight into how complaints are handled internally. Hence, the complainant can only infer the fairness of procedures from obvious front-office actions, which only provide little insight into internal procedures.

Although our findings on the relative effects of the justice dimensions on transaction-specific satisfaction correspond with Orsingher, Valentini, and de Angelis (2010), these authors report significant effects for all three dimensions, whereas our study shows interactional $(p=.067)$ and procedural justice as insignificant $(p=.098)$. This insignificance also contradicts the majority of single studies, which may have a methodological reason. A number of single studies do not report bivariate correlation coefficients. Approximating effect size through $\beta$ coefficients yields conservative results. Hence, effect sizes are attenuated, and weak relationships, such as that between procedural/interactional justice and transaction-specific satisfaction, become insignificant in the path model. Indeed, removing effect sizes that are estimated based on $\beta$ coefficients yields significant paths from interactional $(\beta=.16, p=.007)$ and procedural justice $(\beta=.18, p=.002)$ to transaction-specific satisfaction.

This argument, however, applies to any meta-analysis using SEM and do not explain why Orsingher, Valentini, and de Angelis (2010) report significant effects for interactional and procedural justice. Looking at this study, the authors do not reveal whether they also took the high correlations among the justice dimensions into account. Omitting correlations among justice dimensions in our model actually yields significant effects of interactional justice and procedural justice on transaction-specific satisfaction. Most importantly, however, the authors used the median accumulated sample size $(n=$ 3,214; e.g., Palmatier et al. 2006), which yields large sample sizes and significant path estimates even for weak effects. We used the median sample size (e.g., Kirca, Jayachandran, and Bearden 2005) yielding a smaller sample size $(n=241)$ and significant results for stronger effects only. Taking everything into account we conclude that interactional justice and procedural justice exert a negligible impact, if at all, on transaction-specific satisfaction.

However, our analysis goes beyond these findings in that it also explains if and how justice perceptions directly affect cumulative satisfaction, which is omitted by Orsingher, Valentini, and de Angelis (2010). The results of our study reveal that the common contention of distributive justice to be the most salient determinant of post-complaint satisfaction (e.g., Kau and Loh 2006; Smith, Bolton, and Wagner 1999) is true only for transaction-specific satisfaction. For cumulative satisfaction, however, distributive justice does not play a salient role. Cumulative satisfaction is enhanced by all the three justice dimensions together explaining $63 \%$ of this construct's variance. Interactional justice $(\beta=.41)$, in particular, even exerts a slightly stronger effect than distributive justice $(\beta=.31)$, the effect of procedural justice being weaker $(\beta=.19)$. This means that the overall satisfaction with a provider to date also depends on friendly and polite employee behavior when handling a complaint rather than mainly on the response outcome.

These findings enrich the results reported by Orsingher, Valentini, and de Angelis (2010) in two ways. First, these 
authors infer that service recovery systems only help organizations react to potential problems rather than affect the cumulative assessment of the provider and subsequent repatronage. Our research suggests that this conclusion is premature. As justice perceptions directly affect cumulative satisfaction, which in turn is mainly responsible for repatronage, we can infer that a single recovery perception plays a crucial role in explaining the holistic evaluation of the organization and subsequent repatronage. Second, the role of distributive justice has been shown to be less salient than assumed. Although distributive justice is most important for immediate service recovery, it is even slightly more important for establishing a strong overall relationship that the employee behavior is perceived as polite and friendly (interactional justice).

Further insights are provided by the competing models analysis, which demonstrates that justice perception better explain satisfaction than organizational responses do. This supports the contention that justice perceptions are indeed conceptually different from organizational responses: they are the subjective interpretation of service recovery efforts that are responsible, more than the recovery efforts themselves, for the subsequent satisfaction judgment. Hence, justice perceptions are not a proxy for organizational responses but are the translation of recovery efforts into the customer's language.

Post-complaint satisfaction. Contrary to our expectations, transaction-specific satisfaction has no significant impact on cumulative satisfaction $(\beta=.00, p>.05)$ when estimating the path model. This is surprising given that five of the seven single studies report a significant effect and that the correlation between the two satisfaction constructs is significant in the bivariate analysis. Obviously, justice perceptions predominate in explaining cumulative satisfaction when competing with transaction-specific satisfaction in an overall path model (Maxham III and Netemeyer 2002). This notion is supported when omitting justice perceptions in the competing model analysis: the path from transaction-specific satisfaction to cumulative satisfaction then becomes significant $(\beta=.30, p<.001)$. From an analytical point of view, this means that justice perceptions and transaction-specific satisfaction, which are based on a single recovery event, share a common variance that explains cumulative satisfaction. Yet, when being included conjointly in a path model, transaction-specific satisfaction does not contribute to the explanation of cumulative satisfaction on its own, that is, beyond the contribution of justice perceptions.

Behavioral intentions. Our path model analysis and competing model analysis show that both satisfaction constructs foster behavioral intentions, yet with different strengths. Transactionspecific satisfaction is more important than cumulative satisfaction for explaining positive WOM. Obviously, experiencing satisfactory service recovery is that salient to customers that they are induced to share this experience with other people in their social environment (Maxham III and Netemeyer 2002). Conversely, cumulative satisfaction is a stronger predictor of loyalty than transaction-specific satisfaction. This may be because single transactions are not salient for the decision to continue a relationship. Instead, an overall assessment of all experiences to date is more powerful in predicting customer loyalty (Fournier and Mick 1999). These results further support Orsingher, Valentini, and de Angelis (2010) who also report predominating effects of transaction-specific satisfaction on WOM and of cumulative satisfaction on loyalty.

Moderators. Our analysis shows that the relationships between justice perceptions and the two satisfaction constructs are heterogeneous. This finding is in line with Orsingher, Valentini, and de Angelis (2010) who also report heterogeneous effect sizes and examine method and subject as moderators. However, they only report accumulated effects across all relationships, stating that effect sizes are generally inflated in student samples and that there is no such general effect for method. Our analyses allow a more detailed look at single relationships, suggesting that subject, method, industry type, and complaint type exert idiosyncratic moderating effects on the relationships between justice dimensions and satisfaction.

With respect to method, interactional justice has a weaker impact on transaction-specific satisfaction in experiments than in surveys. With respect to cumulative satisfaction, distributive justice has a larger and procedural justice a weaker impact in experiments than in surveys. These findings may be due to the artificial nature of scenario experiments commonly used in post-complaint studies (all experiments included in the moderator analysis are scenario based). Study subjects are usually asked to put themselves in the position of another person presented in a scenario and to projectively assess customer reactions to fictive organizational responses (e.g., Blodgett and Tax 1993). In such situations, subjects typically read fast through somewhat bland scenarios and are more likely to keep in mind obvious compensation amounts rather than descriptions of factors such as timeliness or friendliness. Hence, experiments tend to inflate (attenuate) the real-life effect of distributive justice (procedural and interactional justice).

With respect to subject, students pay less attention to procedural justice than nonstudents when judging transactionspecific and cumulative satisfaction. Instead, students pay more attention to distributive justice when assessing cumulative satisfaction. This may be because students have a lower financial budget than other population, and this drives them to consider tangible recovery outcomes as more important. In exchange for the tangible outcome, they might accept suboptimal procedures applied to receive this outcome. Moreover, outcomes (i.e., grades) play a predominant role in measuring students' performance. Hence, it is not surprising that satisfaction for students is driven mainly by the complaint outcome (distributive justice). Looking conjointly at the moderating effects of method and subject reveals a confounding effect: experiments are usually conducted with students and surveys with nonstudents. Hence, the inflation (attenuation) of distributive (procedural) justice in student samples may just be due to the scenario-based (i.e., quasi-experimental) character of the studies using student samples. 
With respect to industry type, moderator analysis shows that interactional justice is more important for predicting cumulative satisfaction in service settings than in non-service settings. This finding can be explained by the nature of service settings, which require more frequent and more intense employee-consumer interactions than non-service settings. Consequentially, interactional justice plays a more important role in service industries than in other industries. An alternative explanation is that customers in service settings often complain about processes, such as slow service or rude treatment (nonmonetary complaint), rather than about outcomes, such as missing product or service delivery (monetary complaint). Hence, they would particularly appreciate a polite and respectful treatment. Indeed, moderator analysis for complaint type shows that interactional justice plays a significant role for (transaction-specific) satisfaction in a nonmonetary complaint situation, whereas it has no effect in a monetary complaint situation.

\section{Implications for Researchers}

Our findings enable formulation of recommendations for researchers on how to improve study design and explore new fields of research. The first implication follows from the low variance explained of distributive and procedural justice. To better understand the drivers of justice perceptions, researchers should enrich and refine the set of organizational responses. With regard to distributive justice, extant research focuses on restoring equity through compensation. This leads to the question of what exactly the reference point for equity (and subsequent distributive justice) is. Is it just the purchase price or do complainants expect additional compensation for the damage caused by the failure? In answering this question, researches are able to identify the optimum scope of compensation necessary for establishing distributive justice. Moreover, research may involve other resource exchange principles apart from equity (Smith, Bolton, and Wagner 1999), such as equality, which stresses equal compensation for all customers. Including other distribution principles may help to better explain preferences for different types of compensation (e.g., cash refund vs. exchange). Finally, research should examine if and in what way specific failure-induced emotions, like anger or embarrassment, lead to biased justice evaluations.

As for procedural justice, there are more organizational responses conceivable, such as convenience, flexibility, follow-up contact, and process transparency, which might add to explaining this justice dimension. Other potential drivers of procedural justice can be derived from fairness theory: decision and process control, individual versus consistent problem solving, and conformance of interest between company and consumer (Lind and Tyler 1988; Thibaut and Walker 1975).

The second implication follows from the high correlations between the justice dimensions, which call the three-partite justice conception into question. In justice theory, dependencies among justice dimensions are widely discussed. Folger (1987), for instance, argues that an unfair process decreases distributive justice. Hence, researchers have to take such correlations into account with appropriate statistical methods like SEM, which was done in only 7 of the 18 samples. Using regression analysis may yield biased estimates due to the high multicollinearity (Jain 1996).

The third implication follows from the distinction between transaction-specific satisfaction and cumulative satisfaction. Our results suggest that researchers should not use transaction-specific satisfaction as a proxy for cumulative satisfaction when assessing the effects of service recovery efforts. Both are distinct constructs with the effect sizes of their antecedents (justice perceptions) and consequences (behavioral intentions) differing remarkably. Hence, further post-complaint research should include both constructs. Researchers who only include transaction-specific satisfaction may run the risk of overestimating (underestimating) the effect of distributive (interactional) justice.

The fourth implication results from moderator analysis. When interpreting the effects of the justice dimensions, researchers should be aware that these effects are subject to study characteristics in general and subject in particular. Researchers conducting quasi-experimental studies with students systematically overestimate (underestimate) the effect of distributive (procedural) justice. Hence, further research should use nonstudent samples or rerun student-based experiments on "real" consumers and then compare research findings across samples. This would uncover sample-based biases and increase the external validity of findings.

Experimental work should-if at all using student samples - ensure ecological validity. The respective experiments should induce the same set of inconvenience and annoyance that would occur in "real life," which is required to adequately express more emotionally laden and subtle perceptions such as interactional or procedural justice. This goal could be achieved by carrying out experimental treatments with video vignettes that visualize a real consumption experience (e.g., Dallimore, Sparks, and Butcher 2007) or by conducting real-life experiments using actors playing the roles of service employees (e.g., Hennig-Thurau et al. 2006). Alternatively, researchers could use 3-D animation and virtual worlds in a computer-aided context. Subjects may be assigned an avatar who complains about a service failure (e.g., delay of a flight). Then, virtual service employees may take some action (e.g., apologizing), and the subject has to indicate his or her reactions. Such experiments, though more laborious, would increase realism without giving up the advantage of experiments over surveys (i.e., systematically varying independent variables).

\section{Implications for Managers}

Our findings enable formulation of recommendations for successful service recovery. Indirect effects analysis shows that all three organizational responses affect loyalty as well as positive WOM. Hence, to ensure repurchase and positive WOM, companies should at any rate reimburse complainants for their loss (compensation), treat them with courtesy and respect 
(favorable employee behavior), and establish procedures that facilitate easy and prompt complaint handling (organizational procedures).

When using these recovery efforts, managers should be aware of two issues. First, complainants translate these efforts into justice perceptions. Therefore, managers should not only focus on the recovery effort itself but also on justice perceptions. It is the customer, not the company, who decides what is fair. Organizations that ignore customer perceptions run the risk of thinking they responded properly, while in reality, the customers are still upset and engage in unfavorable actions. Second, managers should be aware that organizational responses are not perceived as isolated actions because the revealed cross-effects indicate that the organizational responses affect all justice dimensions. This holds particularly true for organizational procedures, which need to be designed in a way that they facilitate compensation and favorable employee behavior.

To facilitate compensation, organizational procedures should, for instance, not prescribe a certain compensation form but allow employees to ask complainants about their expectations concerning an adequate problem solution. Such customer integration is important because organizations might favor forms that foster lock-in effects (e.g., voucher or discount on another purchase, replacement, and upgrade), whereas they might refrain from forms that do not entail such effects, but which may be favored by consumers (e.g., discount on the defective product and refund). Offering a choice also gives complainants control over the recovery procedure (Chang 2008).

To facilitate favorable employee behavior, organizational procedures should, for instance, indicate the response times for reactions to complaints (e.g., response to an e-mail within 1 day). Such fast reactions foster the perception that employees are concerned with the customer's problem and that customers are treated in a respectful way. Organizational procedures should also be appropriate to even motivate minimum wage employees to react in a friendly manner to complaints and to anticipate customer needs. This could be achieved, for instance, by an incentive system that rewards frontline employees based on the degree of post-complaint satisfaction. For this purpose, an external market research company could call complainants 3 weeks after the complaint had been filed and ask them about their satisfaction with complaint handling. Moreover, employees should receive guidance on how and when to apologize. Although research consistently shows that an apology has a positive main effect on justice perceptions (Liao 2007; Smith, Bolton, and Wagner 1999) and satisfaction (Mattila, Cho, and Ro 2009; Wirtz and Mattila 2004), it may actually be harmful in some situations. For instance, a complainant who expects compensation, but does not receive any, might infer that the employee is making fun of him.

In practice, only $5 \%$ of complainants report that they had received an apology (Customer Care Alliance 2003). This may be because frontline employees perceive apologizing as an admission of guilt even if they are not to be blamed for the failure. Another reason may be that apologizing comprises high psychological effort and risk for the person apologizing (Walster, Berscheid, and Walster 1973). Hence, organizations should teach service employees that an apology, though entailing such risk, helps de-escalate critical situations that imply high amounts of stress and therefore have negative effects on the employees themselves (Bowen and Johnston 1999).

Other managerial implications follow from the moderator analysis: organizations should design their recovery efforts depending on target group (student vs. nonstudent), industry (service vs. non-service), and complaint type (monetary vs. nonmonetary). Students are a target group with a small financial budget. For such target groups, remuneration is more important than for others, whereas it is less important to provide adequate complaint procedures. Hence, companies should focus on a generous recompense, rather than on a prompt and smooth failure reparation procedure.

Moderator analyses for industry and complaint type suggest that interactional justice is particularly important in service industries and for nonmonetary complaints. This may be because service industries naturally face many employeecustomer interactions, and failures are often nonmonetary (e.g., waiting in line for a long time; Estelami 2000). Hence, organizations in the service industry should carefully train their employees in polite and respectful communication with complainants.

\section{Limitations and Further Research}

Our study has some limitations, which require further research. First, we conceptualize cumulative post-complaint satisfaction as an overall assessment of the entire product/service or organization. Satisfaction with the product/service may actually represent a less holistic assessment than satisfaction with the organization. Hence, future research may distinguish between three satisfaction levels: satisfaction with recovery, with product/service, and with the entire organization.

Second, in many situations the appropriate level of compensation is fairly obvious (e.g., refunding the ticket price when a concert is cancelled). However, compensation level is hard to determine in the case of process failures (e.g., long waiting time). Further research should put more focus on the interaction of failure type and compensation level (e.g., Smith, Bolton, and Wagner 1999).

Third, the results may be biased due to omitted variables. In particular, emotions appear to significantly affect postcomplaint customer reactions. Given the unclear position of emotions within the proposed framework as antecedents to (e.g., Schoefer 2008) or in lieu (e.g., Chebat and Slusarczyk 2005) of post-complaint satisfaction, further research should clarify whether these constructs contribute to the explanation of satisfaction and behavioral intentions over and above the predictive power of justice perceptions.

Fourth, some moderators could not be examined in our analysis because they are addressed only in a few studies: failure magnitude (e.g., Smith, Bolton, and Wagner 1999), switching 
barriers (Valenzuela, Pearson, and Epworth 2005), online versus offline complaint handling (Holloway and Beatty 2003), relationship quality (Grégoire and Fisher 2008), and culture (Patterson, Cowley, and Prasongsukarn 2006).

Fifth, our conceptualization of positive WOM, which represents the majority of single study conceptualizations, is a double question (likelihood of WOM plus positive valence). As this may skew the results, future research should draw on the likelihood and the valence of WOM as separate constructs (e.g., Davidow 2000). Another issue with respect to WOM is the point of time it takes place. While positive WOM may only occur after an appropriate organizational response has taken pace, negative WOM can occur prior to a complaint (i.e., as an immediate reaction to a failure) as well as after an organizational response has taken place (i.e., as a reaction to an unsuccessful recovery effort). Given that the first type of negative WOM is a default (i.e., a natural reaction to a service failure), only the latter type of negative WOM is clearly caused by (inefficient) recovery efforts. Hence, further research should distinguish between the two types of negative WOM using a longitudinal experiment. Surveys may also be conducted on a longitudinal basis, by establishing a customer panel with subjects reporting on their WOM behavior prior to a complaint as well as after the service recovery effort.

\section{Acknowledgments}

The authors thank three anonymous reviewers for their insightful and helpful comments on this article.

\section{Declaration of Conflicting Interests}

The author(s) declared no potential conflicts of interests with respect to the authorship and/or publication of this article.

\section{Funding}

The author(s) received no financial support for the research and/or authorship of this article.

\section{Notes}

1. Colquitt (2001) proposes to split interactional justice into interpersonal and informational justice. However, only very few studies use these dimensions (e.g., Kau and Loh 2006; Mattila 2006). As the aim of this study is to integrate current research, the focus is on distributive, procedural, and interactional justice.

2. As opposed to other meta-analyses in marketing (e.g., Kirca, Jayachandran, and Bearden 2005; Palmatier et al. 2006), the Fisher $\mathrm{z}$ transformation was not used here for two reasons. Using simulations, Callender and Osburn (1980) show that the Fisher $\mathrm{z}$ transformed correlation coefficients severely underestimate the true variance of the correlation coefficients. Moreover, Field (2001) shows that using the Fisher $\mathrm{z}$ transformation for heterogeneous effect sizes overestimates the true effect size by about $15 \%$ to $45 \%$. Heterogeneous effect sizes are common in marketing metaanalyses (e.g., Kirca, Jayachandran, and Bearden 2005; Palmatier et al. 2006), which holds good for the data presented here (see $\chi^{2}$ values in Table 2).
3. As stated in the theoretical section, the likelihood of negative WOM was excluded in the overall model because it may as well occur prior to - or in lieu of - a complaint. Nonetheless, four experimental studies clearly drew on negative WOM that occurs subsequent to ineffective recovery efforts after a complaint. Using these studies, we were able to calculate a partial model including relationships from both satisfaction constructs to loyalty, positive WOM, and negative WOM. In this partial model, the path coefficients between the two satisfaction constructs and positive WOM are the same as in the main model, with the effect of transactionspecific satisfaction being significantly larger $(\beta=.53, p<.001)$ than the effect of cumulative satisfaction $\left(\beta=.20, p<.001 ; \chi^{2}\right.$ $\operatorname{diff}[1]=10.733, p<.001)$. The values of the path coefficients from transaction-specific satisfaction $(\beta=-.57, p<.001)$ and cumulative satisfaction $(\beta=-.34, p<.001)$ on negative WOM $\left(\chi^{2} \operatorname{diff}[1]\right.$ $=8.127, p<.004$ ) follow the same pattern.

\section{References}

Adams, Stacy J. (1965), "Inequity in Social Exchange," in Advances in Experimental Social Psychology, Vol. 2, Leonard Berkowitz, ed. New York, NY: Academic Press, 267-299.

Akaike, Hirotugu (1987), "Factor Analysis and AIC," Psychometrika, 52 (3), 317-332.

Bagozzi, Richard P. (1983), "Issues in the Application of Covariance Structure Analysis: A further Comment," Journal of Consumer Research, 9 (March), 449-450.

Bagozzi, Richard P. and Hans Baumgartner (1996), "The Evaluation of Structural Equation Models and Hypothesis Testing," in Principles of Marketing Research, 1st reprint, Richard P. Bagozzi, ed. Cambridge, UK: Blackwell, 386-422.

Baron, Reuben M. and David A. Kenny (1986), “The Moderator-Mediator Variable Distinction in Social Psychological Research: Conceptual, Strategic, and Statistical Considerations," Journal of Personality and Social Psychology, 51 (6), 1173-1182.

Bies, Robert J. and Debra L. Shapiro (1987), "Interactional Fairness Judgments: The Influence of Causal Accounts," Social Justice Research, 1 (2), 199-218.

Blodgett, Jeffrey G. and Ronald D. Anderson (2000), “A Bayesian Network Model of the Consumer Complaint Process," Journal of Service Research, 2 (May), 321-338.

Blodgett, Jeffrey G., Donald H. Granbois, and Rockney G. Walters (1993), "The Effects of Perceived Justice on Complainants' Negative Word-of-Mouth Behavior and Repatronage Intentions," Journal of Retailing, 69 (4), 399-428.

Blodgett, Jeffrey G., Donna J. Hill, and Stephen S. Tax (1997), “The Effects of Distributive, Procedural, and Interactional Justice on Postcomplaint Behavior," Journal of Retailing, 73 (2), 185-210.

Blodgett, Jeffrey G. and Stephen S. Tax (1993), “The Effects of Distributive and Interactional Justice on Complainants' Repatronage Intentions and Negative Word-of-Mouth Intentions," Journal of Consumer Satisfaction, Dissatisfaction and Complaining Behavior, 6, 100-110.

Bowen, David E. and Robert Johnston (1999), "Internal Service Recovery: Developing a New Construct," International Journal of Service Industry Management, 10 (2), 118-131. 
Callender, John C. and H. G. Osburn (1980), "Development and Test of a New Model for Validity Generalization," Journal of Applied Psychology, 65 (5), 543-558.

Chang, Chia-Chi (2008), "Choice, Perceived Control, and Customer Satisfaction: The Psychology of Online Service Recovery," CyberPsychology \& Behavior, 11 (3), 321-328.

Chebat, Jean-Charles and Witold Slusarczyk (2005), "How Emotions Mediate the Effects of Perceived Justice on Loyalty in Service Recovery Situations: An Empirical Study," Journal of Business Research, 58 (5), 664-673.

Cohen, Jacob (1988), Statistical Power Analysis for the Behavioral Sciences. Hillsdale, NJ: Lawrence Erlbaum Associates.

Colquitt, Jason A. (2001), "On the Dimensionality of Organizational Justice: A Construct Validation of a Measure," Journal of Applied Psychology, 86 (3), 386-400.

Customer Care Alliance (2003), Customer Care-The Multibillion Dollar Sinkhole. http://www.ccareall.org/

Dallimore, Karen S., Beverly A. Sparks, and Ken Butcher (2007), "The Influence of Angry Customer Outbursts on Service Providers' Facial Displays and Affective States," Journal of Service Research, 10 (1), 78-92.

Davidow, Moshe (2003a), “Organizational Responses to Customer Complaints: What Works and What Doesn't," Journal of Service Research, 5 (February), 225-250.

Davidow, Moshe (2003b), "Have You Heard the Word? The Effect of Word of Mouth on Perceived Justice, Satisfaction and Repurchase Intentions Following Complaint Handling," Journal of Consumer Satisfaction, Dissatisfaction and Complaining Behavior, 16, 67-81.

Davidow, Moshe (2000), “The Bottom Line Impact of Organizational Responses to Customer Complaints," Journal of Hospitality and Tourism Research, 24 (4), 473-490.

de Ruyter, Ko and Martin Wetzels (2000), "Customer Equity Considerations in Service Recovery: A Cross-Industry Perspective," International Journal of Service Industry Management, 11 (1), 91-108.

del Río-Lanza, Ana B., Rodolfo Vázquez-Casielles, and Ana M. Díaz-Martín (2009), "Satisfaction with Service Recovery: Perceived Justice and Emotional Responses," Journal of Business Research, 62 (8), 775-781.

DeWitt, Tom, Doan T. Nguyen, and Roger Marshall (2008), “Exploring Customer Loyalty Following Service Recovery: The Mediating Effects of Trust and Emotions," Journal of Service Research, 10 (February), 269-281.

Estelami, Hooman (2000), "Competitive and Procedural Determinants of Delight and Disappointment in Consumer Complaint Outcomes," Journal of Service Research, 2 (February), 285-300.

Field, Andy P. (2001), "Meta-Analysis of Correlation Coefficients: A Monte Carlo Comparison of Fixed- and Random-Effects Methods," Psychological Methods, 6 (2), 161-180.

Folger, Robert (1987), "Distributive and Procedural Justice in the Workplace," Social Justice Research, 1 (2), 143-159.

Fornell, Claes (1983), "Issues in the Application of Covariance Structure Analysis: A Comment," Journal of Consumer Research, 9 (March), 443-448.

Fournier, Susan and David G. Mick (1999), "Rediscovering Satisfaction," Journal of Marketing, 63 (October), 5-23.
Gerbing, David W. and James C. Anderson (1984), "On the Meaning of Within-Factor Correlated Measurement Errors," Journal of Consumer Research, 11 (June), 572-580.

Geyskens, Inge, Jan-Benedict E. M. Steenkamp, and Nirmalya Kumar (1999), “A Meta-Analysis of Satisfaction in Marketing Channel Relationships," Journal of Marketing Research, 36 (May), 223-238.

Gilly, Mary C. (1987), "Postcomplaint Processes: From Organizational Response to Repurchase Behavior," Journal of Consumer Affairs, 21 (2), 293-313.

Gilly, Mary C. and Betsy D. Gelb (1982), "Post-Purchase Consumer Processes and the Complaining Consumer," Journal of Consumer Research, 9 (December), 323-328.

Glass, Gene V., Berry McGaw, and Mary L. Smith (1981), Meta-Analysis in Social Research. Newbury Park, CA: SAGE.

Goodwin, Cathy and Ivan Ross (1989), "Salient Dimensions of Perceived Fairness in Resolution of Service Complaints," Journal of Consumer Satisfaction, Dissatisfaction and Complaining Behavior, 2, 87-98.

Grégoire, Yany and Robert J. Fisher (2008), "Customer Betrayal and Retaliation: When Your Best Customers Become Your Worst Enemies," Journal of the Academy of Marketing Science, 36 (Summer), 247-261.

Griffin, Dale W. and Lee Ross (1991), "Subjective Construal, Social Inference, and Human Misunderstanding," in Advances in Experimental Social Psychology, Vol. 24, M. P. Zanna, ed. New York, NY: Academic Press, 319-359.

Hennig-Thurau, Thorsten, Markus Groth, Michael Paul, and Dwayne D. Gremler (2006), "Are all Smiles Created Equal? How Emotional Contagion and Emotional Labor Affect Service Relationships," Journal of Marketing, 70 (July), 58-73.

Hess Jr., Ronald L., Shankar Ganesan, and Noreen M. Klein (2003), "Service Failure and Recovery: The Impact of Relationship Factors on Customer Satisfaction," Journal of the Academy of Marketing Science, 31 (2), 127-145.

Holloway, Betsy B. and Sharon E. Beatty (2003), "Service Failure in Online Retailing," Journal of Service Research, 6 (1), 92-105.

Homburg, Christian and Andreas Fürst (2005), "How Organizational Complaint Handling Drives Customer Loyalty: An Analysis of the Mechanistic and the Organic Approach," Journal of Marketing, 69 (July), 95-114.

Hunter, John E. and Frank L. Schmidt (2004), Methods of Meta-Analysis: Correcting Error and Bias in Research Findings. Thousand Oaks, CA: SAGE.

Hunter, John E., Frank L. Schmidt, and Gregg G. Jackson (1982), Meta-Analysis: Cumulating Research Findings across Studies. Beverly Hills, CA: SAGE.

Jain, Dipak C. (1996), "Regression Analysis for Marketing Decisions," in Principles of Marketing Research, 1st reprint, Richard P. Bagozzi, ed. Cambridge, UK: Blackwell, 162-194.

Johnson, Michael D., Eugene W. Anderson, and Claes Fornell (1995), "Rational and Adaptive Performance Expectations in a Customer Satisfaction Framework," Journal of Consumer Research, 21 (March), 695-707.

Karande, Kiran, Vincent P. Magnini, and Leona Tam (2007), "Recovery Voice and Satisfaction after Service Failure: An Experimental 
Investigation of Mediating and Moderating Factors," Journal of Service Research, 10 (November), 187-203.

Kau, Ah-Keng and Elizabeth Wan-Yiun Loh (2006), “The Effects of Service Recovery on Consumer Satisfaction: A Comparison between Complainants and Non-Complainants," Journal of Services Marketing, 20 (2), 101-111.

Kim, Taegoo, Woo G. Kim, and Hong-Bumm Kim (2009), "The Effects of Perceived Justice on Recovery Satisfaction, Trust, Word-of-Mouth, and Revisit Intention in Upscale Hotels," Tourism Management, 30 (1), 51-62.

Kirca, Ahmet H., Satish Jayachandran, and William O. Bearden (2005), "Market Orientation: A Meta-Analytic Review and Assessment of its Antecedents and Impact on Performance," Journal of Marketing, 69 (April), 24-41.

Liao, Hui (2007), "Do it Right this Time: The Role of Employee Service Recovery Performance in Customer-Perceived Justice and Customer Loyalty after Service Failures," Journal of Applied Psychology, 92 (2), 475-489.

Lind, Edgar A. and Tom R. Tyler (1988), The Social Psychology of Procedural Justice. New York, NY: Plenum Press.

Lipsey, Mark W. and David B. Wilson (2001), Practical Meta-Analysis. Thousand Oaks, CA: SAGE.

Mattila, Anna S. (2006), "The Power of Explanations in Mitigating the Ill-Effects of Service Failures," Journal of Services Marketing, $20(6 / 7), 422-428$.

Mattila, Anna S., Wonae Cho, and Heejung Ro (2009), “The Joint Effects of Service Failure Mode, Recovery Effort, and Gender on Customers' Post-Recovery Satisfaction," Journal of Travel \& Tourism Marketing, 26 (2), 120-128.

Mattila, Anna S. and Paul G. Patterson (2004), "Service Recovery and Fairness Perceptions in Collectivist and Individualist Contexts," Journal of Service Research, 6 (May), 336-346.

Maxham III, James G. and Richard G. Netemeyer (2003), "Firms Reap what they Sow: The Effects of Shared Values and Perceived Organizational Justice on Customers' Evaluations of Complaint Handling," Journal of Marketing, 67 (January), 46-62.

Maxham III, James G. and Richard G. Netemeyer (2002), "Modeling Customer Perceptions of Complaint Handling over Time: The Effects of Perceived Justice on Satisfaction and Intent," Journal of Retailing, 78 (4), 239-252.

McColl-Kennedy, Janet R., Catherine S. Daus, and Beverley A. Sparks (2003), "The Role of Gender in Reactions to Service Failure and Recovery," Journal of Service Research, 6 (August), 66-82.

McCollough, Michael A., Leonard L. Berry, and Manjit S. Yadav (2000), "An Empirical Investigation of Customer Satisfaction after Service Failure and Recovery," Journal of Service Research, 3 (November), 121-137.

Mount, Daniel J. and Anna Mattila (2000), “The Final Opportunity: The Effectiveness of a Customer Relations Call Center in Recovering Hotel Guests," Journal of Hospitality \& Tourism Research, 24 (4), 514-525.

Oliver, Richard L. (1997), Satisfaction: A Behavioral Perspective on the Consumer. Boston, MA: Irwin/McGraw-Hill.

Oliver, Richard L. (1980), "A Cognitive Model of the Antecedents and Consequences of Satisfaction Decisions," Journal of Marketing Research, 17 (November), 460-469.
Olsen, Line L. and Michael D. Johnson (2003), "Service Equity, Satisfaction, and Loyalty: From Transaction-Specific to Cumulative Evaluations," Journal of Service Research, 5 (February), 184-195.

Orsingher, Chiara, Sara Valentini, and Matteo de Angelis (2010), “A Meta-Analysis of Satisfaction with Complaint Handling in Services," Journal of the Academy of Marketing Science, 38 (2), 169-186.

Palmatier, Robert W., Rajiv P. Dant, Dhruv Grewal, and Kenneth R. Evans (2006), "Factors Influencing the Effectiveness of Relationship Marketing: A Meta-Analysis," Journal of Marketing, 70 (October), 136-153.

Patterson, Paul G., Elizabeth Cowley, and Kriengsin Prasongsukarn (2006), "Service Failure Recovery: The Moderating Impact of Individual-Level Cultural Value Orientation on Perceptions of Justice," International Journal of Research in Marketing, 23 (3), 263-277.

Perreault Jr., William D. and Laurence E. Leigh (1989), "Reliability of Nominal Data Based on Qualitative Judgments," Journal of Marketing Research, 26 (May), 135-148.

Peterson, Robert A. and Steven P. Brown (2005), "On the use of Beta Coefficients in Meta-Analysis," Journal of Applied Psychology, 90 (1), 175-181.

Rosenthal, Robert (1979), “The 'File-Drawer Problem' and Tolerance for Null Results," Psychological Bulletin, 86 (3), 638-641.

Schmidt, Frank L. and John E. Hunter (1999), "Comparison of Three Meta-Analysis Methods Revisited: An Analysis of Johnson, Mullen, and Salas (1995)," Journal of Applied Psychology, 84 (1), 144-148.

Schoefer, Klaus (2008), “The Role of Cognition and Affect in the Formation of Customer Satisfaction Judgements Concerning Service Recovery Encounters," Journal of Consumer Behaviour, 7 (May), 210-221.

Smith, Amy K., Ruth N. Bolton, and Janet Wagner (1999), “A Model of Customer Satisfaction with Service Encounters Involving Failure and Recovery," Journal of Marketing Research, 36 (August), 356-372.

Spreng, Richard A., Gilbert D. Harrell, and Robert D. Mackoy (1995), "Service Recovery: Impact on Satisfaction and Intentions," Journal of Services Marketing, 9 (1), 15-23.

Szymanski, David M. and David H. Henard (2001), "Customer Satisfaction: A Meta-Analysis of the Empirical Evidence," Journal of the Academy of Marketing Science, 29 (1), 16-35.

TARP (1981), Measuring the Grapevine-Consumer Response and Word of Mouth. Atlanta, GA: Coca Cola.

Tax, Stephen S., Stephen W. Brown, and Murali Chandrashekaran (1998), "Customer Evaluations of Service Complaint Experiences: Implications for Relationship Marketing," Journal of Marketing, 62 (April), 60-76.

Thibaut, John and Laurens Walker (1975), Procedural Justice: A Psychological Analysis. Hillsdale, NJ: Lawrence Erlbaum Associates.

Valenzuela, Fredy, David Pearson, and Roger Epworth (2005), "Influence of Switching Barriers on Service Recovery Evaluation," Journal of Services Research, Special Issue (December), 239-257. Varela-Neira, Concepción, Rodolfo Vázquez-Casielles, and Víctor Iglesias-Argüelles (2008), "The Influence of Emotions on 
Customer's Cognitive Evaluations and Satisfaction in a Service Failure and Recovery Context," Service Industries Journal, 28 (May), 497-512.

Voorhees, Clay M. and Michael K. Brady (2005), "A Service Perspective on the Drivers of Complaint Intentions," Journal of Service Research, 8 (November), 192-204.

Walster, Elaine, Ellen Berscheid, and G. W. Walster (1973), "New Directions in Equity Research," Journal of Personality and Social Psychology, 25(2), 151-176.

Webster, Cynthia and D. S. Sundaram (1998), "Service Consumption Criticality in Failure Recovery," Journal of Business Research, 41 (2), 153-159.

Weun, Seungoog, Sharon E. Beatty, and Michael A. Jones (2004), "The Impact of Service Failure Severity on Service Recovery Evaluations and Post-Recovery Relationships," Journal of Services Marketing, 18 (2), 133-146.

Wirtz, Jochen and Anna S. Mattila (2004), "Consumer Responses to Compensation, Speed of Recovery and Apology after a Service Failure," International Journal of Service Industry Management, 15 (2), 150-166.
Worsfold, Kate, Jennifer Worsfold, and Graham Bradley (2007), "Interactive Effects of Proactive and Reactive Service Recovery Strategies: The Case of Rapport and Compensation," Journal of Applied Social Psychology, 37 (11), 2496-2517.

\section{Bios}

Katja Gelbrich (katja.gelbrich@tu-ilmenau.de) is a full professor of Marketing at Ilmenau University of Technology, Germany. Her research focuses on service recovery, consumer emotions, crosscultural marketing, and international management. She has published articles in the Journal of the Academy of Marketing Science, Marketing Letters, Schmalenbach Business Review, and Social Psychology.

Holger Roschk (holger.roschk@tu-ilmenau.de) is a PhD candidate at the marketing department at Ilmenau University of Technology, Germany. His research focuses on service recovery and meta-analysis. He has published in Marketing Letters and presented papers at the AMA Educator's Conference and European Marketing Academy Conference. 